First publ. in: Deep Sea Research / 1, 47 (2000), pp. 621-654

\title{
Analysis of deep-water exchange in the Caspian Sea based on environmental tracers
}

\author{
F. Peeters ${ }^{\mathrm{a}, \mathrm{b}, *}$, R. Kipfer ${ }^{\mathrm{a}, \mathrm{b}}$, D. Achermann ${ }^{\mathrm{a}, \mathrm{b}}$, M. Hofer ${ }^{\mathrm{a}, \mathrm{b}}$, \\ W. Aeschbach-Hertig ${ }^{\mathrm{a}, \mathrm{b}}$, U. Beyerle ${ }^{\mathrm{a}, \mathrm{b}}$, D.M. Imboden ${ }^{\mathrm{a}, \mathrm{b}}$, \\ K. Rozanski ${ }^{\mathrm{c}}$, K. Fröhlich ${ }^{\mathrm{d}}$ \\ ${ }^{a}$ Swiss Federal Institute of Technology (ETH), CH-8600 Dübendorf, Switzerland \\ ${ }^{\mathrm{b}}$ Swiss Federal Institute of Environmental Science and Technology (EAWAG), CH-8600 Dübendorf, Switzerland \\ ${ }^{\mathrm{c}}$ Faculty of Physics and Nuclear Techniques, University of Mining and Metallurgy, Krakow, Poland \\ ${ }^{\mathrm{d}}$ International Atomic Energy Agency, Department of Research and Isotopes, Vienna, Austria
}

Received 24 June 1998; received in revised form 15 June 1999; accepted 15 June 1999

\begin{abstract}
In order to quantify deep-water exchange in the Caspian Sea, the world's largest inland water body, water samples were analyzed for the transient tracers ${ }^{3} \mathrm{H},{ }^{3} \mathrm{He},{ }^{4} \mathrm{He}, \mathrm{CFC}-11, \mathrm{CFC}-12$ and atmospheric noble gases. Measurements of temperature, salinity (calculated from conductivity for the ionic composition of Caspian Sea water), and dissolved oxygen were employed to investigate the processes responsible for deep-water renewal. The Caspian Sea consists of two deep basins, the southern and central basins, separated by a sill, and a shallow northern basin. The deep water (below $200 \mathrm{~m}$ ) accounts for almost $60 \%$ of the total water mass. Below $200 \mathrm{~m}$ the concentrations of ${ }^{3} \mathrm{H}$ and ${ }^{3} \mathrm{He}$ are much lower in the southern basin than at the same depths in the central basin, but this is not the case for either of the CFCs. However, apparent water ages calculated from ${ }^{3} \mathrm{H}-{ }^{3} \mathrm{He}$ and from $\mathrm{CFC}-12$ concentrations are the same for the deep water of the southern and central basins, and yield deep-water exchange rates of approximately $7 \%$ per year for each of the two basins. This implies volume fluxes across the $200-\mathrm{m}$ level of about $2220 \mathrm{~km}^{3} \mathrm{yr}^{-1}$ within the southern basin and $770 \mathrm{~km}^{3} \mathrm{yr}^{-1}$ within the central basin. Based on the apparent water ages, the oxygen depletion in the deep water is estimated to be about $0.35 \mathrm{mg}^{-1} \mathrm{yr}^{-1}$. The processes responsible for deep-water exchange have not yet been identified conclusively. However, vertical temperature and salinity gradients observed during two expeditions, in September 1995 and 1996, suggest that within the southern and central basins large-scale convection cannot be triggered by seasonal cooling alone, but requires the surface water to be cold/saline or to contain high suspended sediment loads. In the central basin the increase in salinity occurring during ice formation in early winter is possibly sufficient to cause
\end{abstract}

\footnotetext{
* Corresponding author. Fax: 0041-1-823-5210.

E-mail address: peeters@eawag.ch (F. Peeters)
} 
convection. In late summer, the horizontal transport of water from the upper $170 \mathrm{~m}$ of the central basin into the southern basin results in mixing down to $400 \mathrm{~m}$. In winter this process might result in convection down to the maximum depth. Alternatively, the data are also consistent with the hypothesis that rare events cause large-scale convection down to the maximum depth in the southern and in the central basin simultaneously, followed by slight mixing that mainly affects only the top $500 \mathrm{~m}$. According to apparent water ages from below $500 \mathrm{~m}$, the last such major mixing event could have occurred in 1976 shortly before the water level of the Caspian Sea began to rise.

Keywords: Casapian Sea; Deep-water exchange; Chlorofluorocarbon; Helium; Tritium

\section{Introduction}

The Caspian Sea, having a volume of $78,000 \mathrm{~km}^{3}$ and a surface area of $3.8 \times$ $10^{5} \mathrm{~km}^{2}$ is the largest inland water body on earth. A southern, a central and a northern basin are commonly distinguished (Fig. 1 and Table 1). Southern and central basins, with a maximum water depths of 1024 and $788 \mathrm{~m}$, respectively, are separated by a sill with a maximum depth of about $170 \mathrm{~m}$. The northern basin, with a maximum depth of about $20 \mathrm{~m}$, is a very shallow extension of the central basin. The Caspian Sea water has a salinity ranging from 5 to $13 \mathrm{~g} \mathrm{~kg}^{-1}$, with the lowest values occurring in the northern basin. The main inflow is the River Volga, which discharges into the northern basin, contributing about $65 \%$ of the total water inflow (precipitation plus total river inflow is about $370 \mathrm{~km}^{3} \mathrm{yr}^{-1}$ ). Water loss is mainly by evaporation (about $380 \mathrm{~km}^{3} \mathrm{yr}^{-1}$ ), direct outflow into the Kara Bogaz Bay being slight ( 0 to $20 \mathrm{~km}^{3} \mathrm{yr}^{-1}$ ) (see Table 1).

The Caspian Sea is of great economic importance and hence exposed to intense industrial use. Within and close to the Caspian Sea, oil fields have been exploited since the turn of the century. With the discovery of new oil resources in Kazakhstan, which are expected to be comparable in size to those of the Persian Gulf, the Caspian Sea region becomes more important for oil transport. A major oil pipeline from Kazakhstan to Baku has already been projected to run through the northern and central basin of the Caspian Sea. The second largest industry in the Caspian Sea is caviar production, with a yearly turnover of 400 million \$. The fishing industry depends on an intact eco-system and therefore is in conflict with the oil industry and other industries affecting the quality of the sea water.

In recent years research on the Caspian Sea has been concentrated on sea level fluctuations. From 1930 to 1977 the sea level decreased by about 3 m, which resulted in a reduction of surface area by about $48,000 \mathrm{~km}^{2}$. The economic consequences were severe, because shallow waters, especially in the northern basin, hindered maritime transport, and ground water levels dropped, resulting in a drastic reduction of agricultural productivity. Since 1978 the sea level has increased rapidly by about $2.5 \mathrm{~m}$ and threatens to reach a level of $-25 \mathrm{~m}$ ( $25 \mathrm{~m}$ below Baltic Sea level), at which heavily polluted oil fields and industrial areas including a nuclear power plant at 


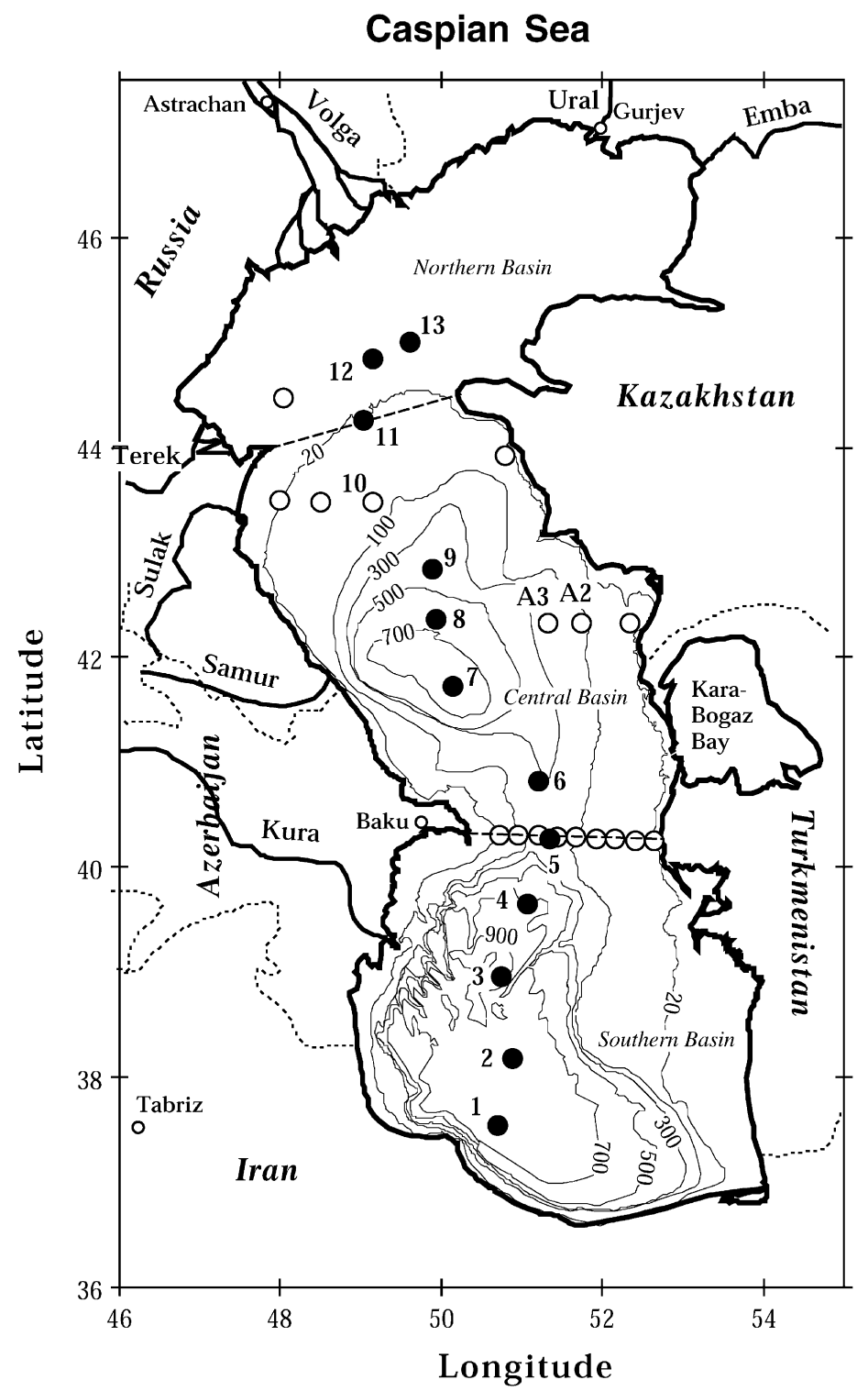

Fig. 1. Map of the Caspian Sea. Symbols indicate sampling stations of the expeditions in 1995 (solid circles) and 1996 (solid and open circles). The dashed lines indicate the limits between the basins.

Aktau in Kazakhstan (Dumont, 1995) would be flooded. A sea level of -25 m would result in a loss of industries, infrastructure and about $15,000 \mathrm{~km}^{2}$ of agriculturally used land in Russia and Kazakhstan. According to Rodionov (1994) the sea level fluctuations of the Caspian Sea are caused by variations in the inflows, which are the 
Table 1

Some morphometric and hydrological characteristics of the Caspian Sea (based on Kosarev and Yablonskaya, 1994)

\begin{tabular}{|c|c|}
\hline Surface area & $379,000 \mathrm{~km}^{2}$ \\
\hline Volume & $78,000 \mathrm{~km}^{3}$ \\
\hline \multicolumn{2}{|l|}{ Maximum depth } \\
\hline Southern basin & $1024 \mathrm{~m}$ \\
\hline Central basin & $788 \mathrm{~m}$ \\
\hline Northern basin & $20 \mathrm{~m}$ \\
\hline \multicolumn{2}{|l|}{ Mean depth } \\
\hline Southern basin & $342 \mathrm{~m}$ \\
\hline Central basin & $197 \mathrm{~m}$ \\
\hline Northern basin & $4.4 \mathrm{~m}$ \\
\hline \multicolumn{2}{|l|}{ Area of interface between } \\
\hline Southern and central basin & $15.6 \mathrm{~km}^{2}$ \\
\hline Central and northern basin & $3.3 \mathrm{~km}^{2}$ \\
\hline \multicolumn{2}{|l|}{ Length of interface between } \\
\hline Southern and central basin & $220 \mathrm{~km}$ \\
\hline Central and northern basin & $200 \mathrm{~km}$ \\
\hline \multicolumn{2}{|c|}{ Water balance (annual mean 1900 to 1990 ) } \\
\hline Riverine inflow & $292 \mathrm{~km}^{3} \mathrm{yr}^{-1}$ \\
\hline Precipitation & $77 \mathrm{~km}^{3} \mathrm{yr}^{-1}$ \\
\hline Outflow to Gara Bogaz Bay & $0-22 \mathrm{~km}^{3} \mathrm{yr}^{-1}$ \\
\hline Evaporation & $377 \mathrm{~km}^{3} \mathrm{yr}^{-1}$ \\
\hline Catchment area & $3.5 \times 10^{6} \mathrm{~km}^{2}$ \\
\hline Salinity (average) & $12.3 \mathrm{~g} \mathrm{~kg}^{-1}$ \\
\hline Mean annual surface temperature & $13^{\circ} \mathrm{C}$ \\
\hline
\end{tabular}

result of natural fluctuations in the climate of the northern hemisphere. In addition, the extensive use of Volga water for irrigation (Klinge and Myagkov, 1992) and a probable decrease in evaporation due to surface oil films has affected the sea level.

Besides sea level fluctuations the pollution of the Caspian Sea becomes an increasing problem. Heavy metals, hydrocarbons, pesticides, nutrients such as phosphate and nitrate, and other human wastes are introduced into the Caspian Sea close to the sea surface by river inflows and by direct waste dumping from oil-rigs and oil industries.

In the Caspian Sea convective transport in spring and fall causes a distribution and dilution of the pollutants within the top $200 \mathrm{~m}$ (seasonal mixed layer). However, the deep water below $200 \mathrm{~m}$ accounts for about $60 \%$ of the total water mass. How strongly the deep water is affected by pollutants and how much deep water contributes to the dilution of pollutants and nutrients in the surface region depends on the rate of deep-water renewal. Oxygen concentrations are at about 2 to $3 \mathrm{mg} 1^{-1}$ in the deepest region of the Caspian Sea (IAEA, 1996), suggesting a regular but moderate renewal of the deep-water body. 
In this investigation we quantify deep-water renewal rates based on measurements of transient tracers. Combined with the analysis of CTD-measurements we will identify transport mechanisms and mixing scenarios that most likely are responsible for the exchange of deep water by surface water in the Caspian Sea.

The next section gives an overview of the field data. Then we describe how salinity and density can be calculated from CTD-measurements for the brackish Caspian Sea water. Results from CTD-casts and measurements of transient tracers are presented followed by an estimation of apparent water age and a calculation of deep-water renewal rates. In the last section we discuss possible mechanisms for deep-water renewal.

\section{Field data and equation of state}

\subsection{Field campaigns}

The data presented here were collected during two cruises on the Caspian Sea that were organized and conducted by the International Atomic Energy Agency (IAEA), Vienna, in September 1995 and 1996. In 1995 stations marked with a solid circle (Fig. 1) were sampled and in 1996 measurements were conducted at all sampling stations (solid and open circles in Fig. 1) except for station 13. Vertical profiles of temperature $T$, salinity $S,{ }^{4} \mathrm{He}$ concentrations and dissolved oxygen $\left(\mathrm{O}_{2}\right)$ are shown in Fig. 2. The data are from the deepest location of the central basin (station 7 for $T, S$, $\mathrm{O}_{2}$ and station 8 for ${ }^{4} \mathrm{He}$, see Fig. 1) and the southern basin (all tracers from station 3, see Fig. 1), and were collected in 1995.

Temperature, conductivity $\kappa$ and pressure $p$ were obtained by using a EG\&G Ocean Product CTD-probe. Salinity was calculated from $\kappa, T$ and $p$ by using the equation of state for standard sea water (UNESCO, 1981a) and an additional calibration factor that accounts for the difference in ion-composition of Caspian Sea water compared to that of standard sea water. Details of the salinity calibration and the calculation of density from CTD-measurements for Caspian Sea water are discussed below (Section 2.2).

Tritium concentrations were determined from water samples collected at several stations at several depths and in all basins by the laboratories of the IAEA and at ETH/EAWAG. The water samples from the deepest stations of the central and southern basin were analyzed for ${ }^{3} \mathrm{He},{ }^{4} \mathrm{He}$ and $\mathrm{Ne}$ at ETH/EAWAG according to the techniques described by Kipfer et al. (1994). In addition, 6 samples were analyzed for all stable noble gases $\mathrm{He}, \mathrm{Ne}, \mathrm{Ar}, \mathrm{Kr}$ and $\mathrm{Xe}$.

Concentrations of the chlorofluorocarbons CFC-11 $\left(\mathrm{CCl}_{3} \mathrm{~F}\right)$ and CFC-12 $\left(\mathrm{CCl}_{2} \mathrm{~F}_{2}\right)$ were determined for samples collected in 1996 at the deepest station in the southern and in the central basin using the method described by Hofer and Imboden (1998). During transport and storage of the samples oxygen was completely consumed in the sample containers (copper tubes). Because CFC-11 partially decomposes in an oxygen free environment the CFC-11 concentrations were corrected by assuming initial oxygen concentrations to correspond to those from 1995 and by using the rates for 

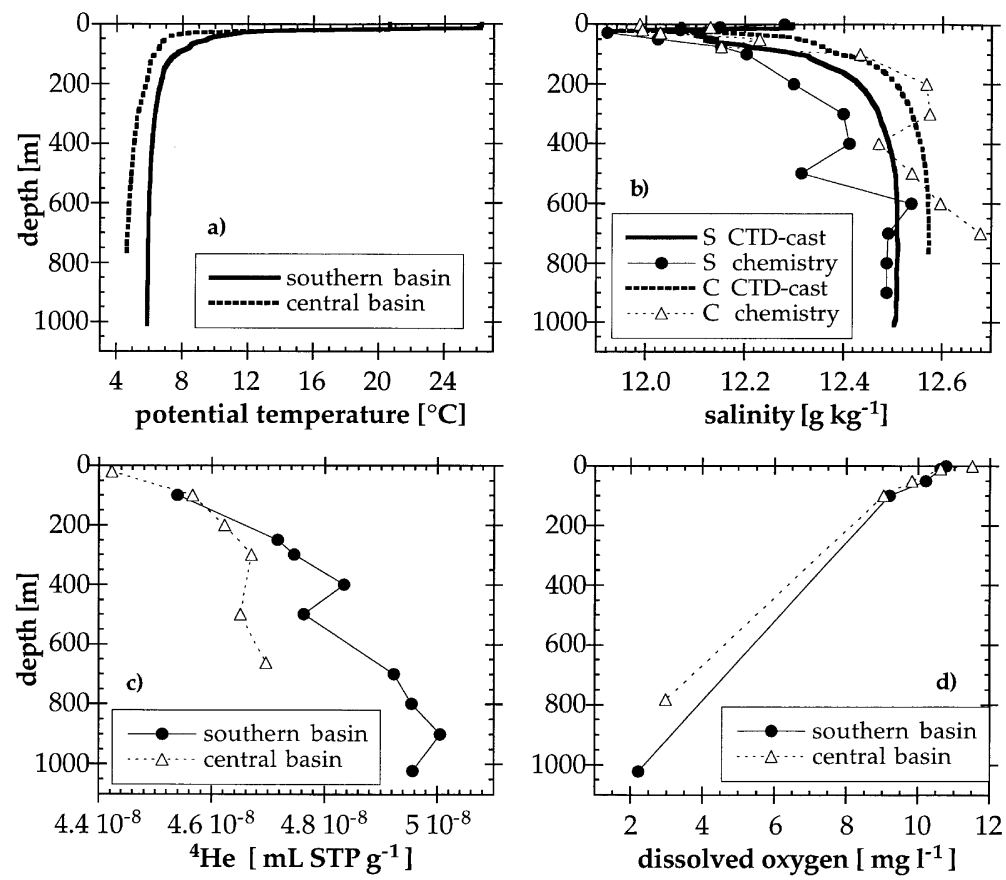

Fig. 2. Temperature, salinity, ${ }^{4} \mathrm{He}$ concentration and dissolved oxygen as function of depth. Data were collected in 1995 at the deepest locations of the southern (station 3) and the central (station 7) basin. ${ }^{4} \mathrm{He}$ data for the central basin are from station $8 . \mathrm{S}$ and $\mathrm{C}$ in (b) stand for southern and central basin, respectively.

oxygen depletion and CFC-11 decay in the copper tubes given by Hofer and Imboden (1998). Decomposition of CFC-12 in the sample containers is negligible due to its very small decomposition rate (Hofer and Imboden, 1998).

Concentrations of CFC-11, CFC-12, ${ }^{3} \mathrm{H},{ }^{3} \mathrm{He},{ }^{4} \mathrm{He}$ and $\mathrm{Ne}$ from the deepest station of the southern and of the central basin are listed in the appendix.

Data on the major ions and on dissolved oxygen were taken from the data report for the 1995 expedition to the Caspian Sea provided by the IAEA (1996). The major ion analysis was carried out for all water samples from 1995 by the Centre of Geochimie de la Surface CNRS France. Dissolved oxygen was determined by the Hydrochemical Laboratory of the State Hydrometeorological Committee, Azerbaijan Republic, using Winkler titration. The oxygen values were reported in $\mathrm{mg}^{-1}$, which can be converted to $\mathrm{mol} \mathrm{kg}^{-1}$ with an accuracy better than $3 \%$ using the conversion factor $3.098 \times 10^{-5} 1 \mathrm{mg}^{-1} \mathrm{~mol} \mathrm{~kg}^{-1}$.

\subsection{Calculation of salinity and density from CTD-measurements}

In ocean studies the calculation of salinity and density from CTD-measurements is usually based on the emprical equations given by UNESCO (1981a,b). Because these empirical relations are valid only for water which has the ion composition of standard 
sea water, they cannot be applied directly to Caspian Sea water. Millero and Chetirkin (1980) have conducted laboratory experiments to provide an empirical equation of state for Caspian Sea water. Unfortunately, the relations of Millero and Chetirkin are valid only at surface pressure, i.e. at $p=0$, and for temperatures $T$ above $5^{\circ} \mathrm{C}\left(5^{\circ} \mathrm{C} \leqslant\right.$ $T \leqslant 35^{\circ} \mathrm{C}$ ).

To provide an equation of state that can serve as a basis for calculation of salinity, stability, potential temperature and density differences in the deep water of the Caspian Sea, we modified the empirical relations for the equation of state for standard sea water on the basis of the ion composition of Caspian Sea water and the molal volumes of binary solutions. At surface pressure salinity and density differences calculated from these equations very closely agree with the corresponding values determined from the empirical relations by Millero and Chetirkin (1980).

\subsubsection{Salinity}

The mean ion composition of Caspian Sea water has been calculated from the chemically determined major ion composition of the samples collected in 1995 (IAEA, 1996) as volume weighted average (Table 2). Morphometric parameters of the Caspian Sea are listed in Table 3. Within a range of $1 \%$ the mol fraction of all major ions is the same in all samples (Table 2). Thus, the elemental ratios of the major ions in all samples is approximately constant.

The calculation of the absolute salinity $S_{\text {chem }}$ (i.e. mass salt per mass solution) from the ion concentrations measured in $\mathrm{moll}^{-1}$ under standard conditions $\left(T=25^{\circ} \mathrm{C}\right.$, $p=0$ ) requires the conversion of molar concentrations $\mathrm{mol}^{-1}$ to dimensions $\mathrm{g} 1^{-1}$ using the molar weights of the ions and the conversion to salinity units $\mathrm{g} \mathrm{kg}^{-1}$ using the density of the solution. The second conversion can be achieved if the functional relationship between density and salinity, i.e. the equation of state, $\rho_{\text {solution }}\left(T, S_{\text {chem }}, p\right)$ is known:

$$
S_{\text {chem }}=\frac{C_{\text {tot }}}{\rho_{\text {solution }}\left(T, S_{\text {chem }}, p\right)}
$$

where $C_{\text {tot }}$ is the total sum of the ion masses per liter solution assuming constant elemental ratios of the major ions. Eq. (1) is an implicit equation for salinity and was solved numerically for the ion concentrations of each sample from the Caspian Sea using the equation of state described below (Section 2.2.2).

Using Eq. (1) for the volume weighted mean ion concentrations (Table 2, column 2) the mean absolute salinity in the Caspian Sea was obtained to be $12.28 \mathrm{~g} \mathrm{~kg}^{-1}$. This salinity is smaller than the values published by Blinov (1962) $\left(S=12.8 \mathrm{~g} \mathrm{~kg}^{-1}\right)$ and by Millero and Chetirkin (1980), who cited Hunt with a value of $13 \mathrm{~g} \mathrm{~kg}^{-1}$. However, the samples of Caspian Sea water measured by Millero and Chetirkin (1980) apparently had a chlorinity of only 4.231 to $5.015 \mathrm{~g} \mathrm{~kg}^{-1}$ (see Table 2 in Millero and Chetirkin, 1980), which is slightly smaller than our value of $5.18 \mathrm{~g} \mathrm{~kg}^{-1}$ for the $\mathrm{Cl}^{-}$concentration. This indicates that the water analyzed by Millero and Chetirkin had a smaller salinity than the mean salinity observed today. Note that the increase in sea level between 1977 and 1995 by almost $3 \mathrm{~m}$ resulted in an increase in the water volume of 


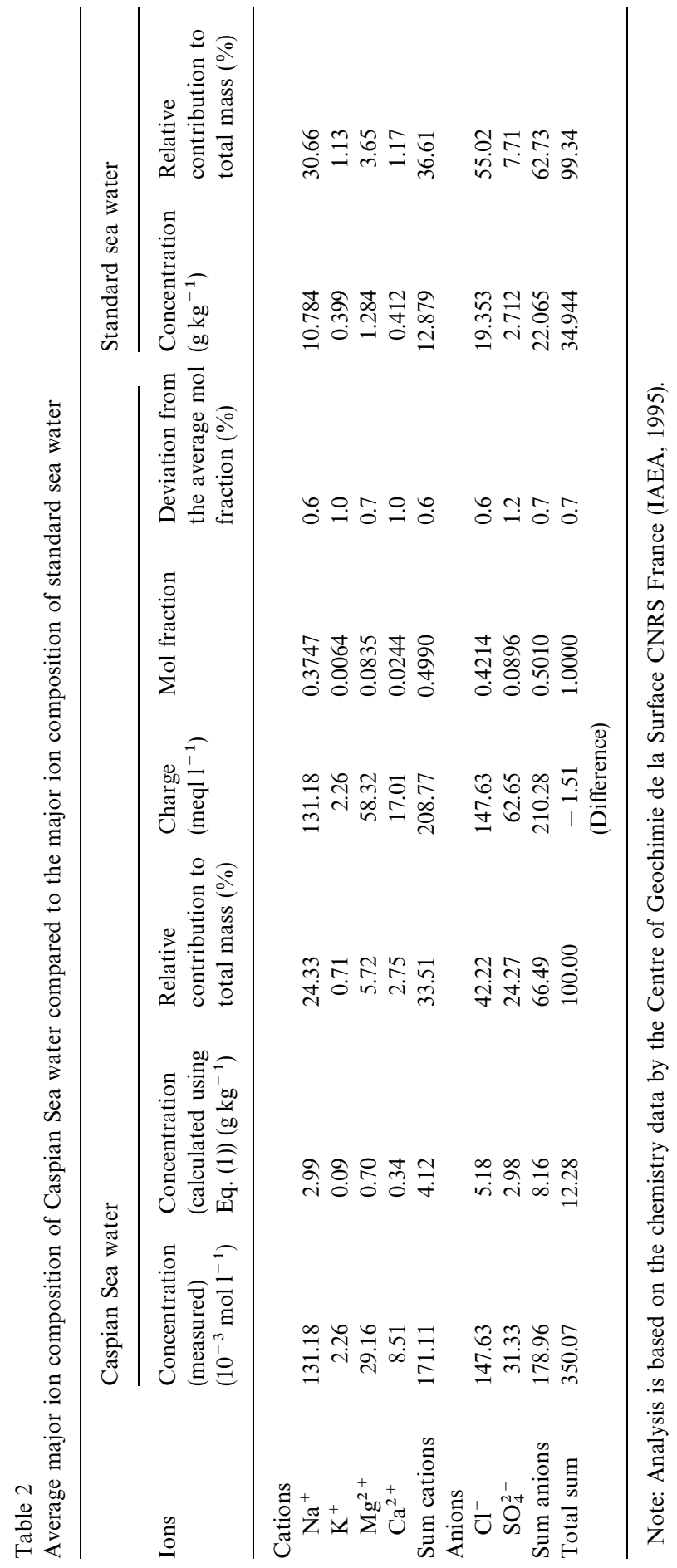


Table 3

Morphometry of the three basins of the Caspian Sea

\begin{tabular}{|c|c|c|c|c|c|c|}
\hline $\begin{array}{l}\text { Depth } \\
{[\mathrm{m}]}\end{array}$ & $\begin{array}{l}\text { Southern Basin } \\
\text { area }\left(\mathrm{km}^{2}\right)\end{array}$ & $\begin{array}{l}\text { Southern Basin } \\
\text { volume }\left(\mathrm{km}^{3}\right)\end{array}$ & $\begin{array}{l}\text { Central Basin } \\
\text { area }\left(\mathrm{km}^{2}\right)\end{array}$ & $\begin{array}{l}\text { Central Basin } \\
\text { volume }\left(\mathrm{km}^{3}\right)\end{array}$ & $\begin{array}{l}\text { Northern Basin } \\
\text { area }\left(\mathrm{km}^{2}\right)\end{array}$ & $\begin{array}{l}\text { Northern Basin } \\
\text { volume }\left(\mathrm{km}^{3}\right)\end{array}$ \\
\hline 0 & 149,000 & 50,900 & 134,000 & 26,400 & 96,300 & 400 \\
\hline 20 & 113,000 & 48,300 & 121,000 & 23,900 & & \\
\hline 50 & 93,200 & 45,200 & 90,200 & 20,700 & & \\
\hline 100 & 79,500 & 40,900 & 63,000 & 16,900 & & \\
\hline 200 & 72,200 & 33,300 & 44,800 & 11,600 & & \\
\hline 300 & 68,900 & 26,300 & 33,200 & 7670 & & \\
\hline 400 & 64,100 & 19,600 & 25,000 & 4770 & & \\
\hline 500 & 57,000 & 13,600 & 18,100 & 2630 & & \\
\hline 600 & 47,900 & 8340 & 12600 & 1100 & & \\
\hline 700 & 37,000 & 4100 & 6240 & 183 & & \\
\hline 800 & 21,400 & 1220 & & & & \\
\hline 900 & 3240 & 123 & & & & \\
\hline 1000 & 50 & 0.4 & & & & \\
\hline
\end{tabular}

Note: Volumes correspond to the total volume below the given depth.

the Caspian Sea by only about $1.1 \%$, which could account for a decrease in salinity of not more than $0.15 \mathrm{~g} \mathrm{~kg}^{-1}$ since 1977 .

Because the ion composition of Caspian Sea water and that of standard sea water are different (see Table 2) the procedure to calculate salinity from CTD-measurements commonly used in the ocean (UNESCO, 1981b) has to be modified to be applicable to Caspian Sea water. For all samples from 1995, with the exception of those from the extremely sharp thermocline, we compared $S_{\text {chem }}$ determined from the major ion analyses by using (1) with the salinity calculated from CTD-measurements using the calibration procedure for standard sea water $S_{\text {sea }}(R, T, p)$ (UNESCO, 1981b). Samples from the thermocline at 20 to $30 \mathrm{~m}$ depth were excluded because a small difference in depth alignment of water sample and CTD-measurement might introduce large errors. $R$ in $S_{\text {sea }}(R, T, p)$ is the ratio of the measured conductivity $\kappa$ at temperature $T$ and pressure $p$ relative to the conductivity of a standardized potassium chloride solution at $p=0$ and $T=15^{\circ} \mathrm{C}$. During the cruises in 1995 and 1996 absolute conductivities were recorded instead of $R$, and the CTD-probe unfortunately was not calibrated against a potassium chloride standard. Therefore, we calculate $R$ via $R=\kappa(S, T, p) / \kappa_{\mathrm{KCl}}$ with $\kappa_{\mathrm{KCl}}=42.9140\left(\mathrm{mS} \mathrm{cm}^{-1}\right)$ (Culkin and Smith, 1980).

The salinity calculated from the CTD measurements using the standard UNESCO (1981b) procedure is systematically smaller than the salinity determined chemically. Best agreement between the two salinities was obtained by introducing a correction factor of $f_{\text {salinity }}=1.1017$ leading to a calibration equation for absolute salinity in the Caspian Sea:

$$
S_{\text {cond }}=1.1017 S_{\text {sea }}\left(\frac{\kappa}{42.9140}, T, p\right) \quad\left(\mathrm{g} \mathrm{kg}^{-1}\right)
$$


where $S_{\text {sea }}$ is calculated from the empirical equations given by UNESCO (1981b). The error in the charge balance of the major ion analysis for the water samples is about 0.5 to $1 \%$, and consequently the error in salinity determined from chemistry should be on the same order. The differences between salinity calculated from CTD-measurements using Eq. (2) $\left(S_{\text {cond }}\right)$ and that calculated from chemistry $\left(S_{\text {chem }}\right)$ fall within this error range and are independent of water pressure, temperature or salinity (Fig. 3a-c), supporting the validity of the calibration procedure.

Application of Eq. (2) to the CTD-measurements from 1996 resulted in mean salinities in the deep water below $500 \mathrm{~m}$ for the central and for the southern basin that were systematically larger by about $1 \%$ than the corresponding values for 1995 . We believe that this systematic bias is due to a shift in the conductivity sensor. Therefore, we adjusted the correction factor and used $f_{\text {salinity }}^{96}=1.0907$ for the CTD-measurements from 1996. This reduced the difference between the deep water (below $500 \mathrm{~m}$ ) salinities from 1995 and 1996 to $0.1 \%$ in the central and in the southern basin. Difficulties with the absolute calibration of conductivity sensors could be avoided in the future by measuring $R$ instead of absolute conductivity as is common practice in oceanography.

\subsubsection{Equation of state}

The equation of state, i.e. density as function of temperature, salinity and pressure, for standard sea water $\rho_{\text {sea }}$ (UNESCO, 1981a) can be adjusted for waters of different ionic composition by calculating a correction factor from the apparent molal volume of the solution under consideration.

In general, density as function of salinity can be written as:

$$
\rho(T, S, p)=\rho(T, 0, p)+\int_{0}^{S}\left(\frac{\partial \rho\left(T, S^{\prime}, p\right)}{\partial S^{\prime}}\right)_{T, p} \mathrm{~d} S^{\prime}
$$

or

with

$$
\rho(T, S, p)=\rho(T, 0, p)+\int_{0}^{S} \rho\left(T, S^{\prime}, p\right) \cdot \beta\left(T, S^{\prime}, p\right) \mathrm{d} S^{\prime}
$$

$$
\beta(T, S, p)=\frac{1}{\rho(T, S, p)}\left(\frac{\partial \rho(T, S, p)}{\partial S}\right)_{T, p},
$$

where $\beta(T, S, p)$ is the haline contraction coefficient. The density for a solution with a given ion composition $\rho_{\text {solution }}(T, S, p)$ can be expressed in terms of the empirical relations for sea water:

$$
\begin{aligned}
& \rho_{\text {solution }}(T, S, p)=\rho_{\text {solution }}(T, 0, p)+\int_{0}^{S} \rho_{\text {solution }}\left(T, S^{\prime}, p\right) \beta_{\text {solution }}\left(T, S^{\prime}, p\right) \cdot \mathrm{d} S^{\prime} \\
= & \rho_{\text {sea }}(T, 0, p)+\int_{0}^{S} \rho_{\text {sea }}\left(T, S^{\prime}, p\right) \beta_{\text {sea }}\left(T, S^{\prime}, p\right) \cdot \frac{\rho_{\text {solution }}\left(T, S^{\prime}, p\right) \beta_{\text {solution }}\left(T, S^{\prime}, p\right)}{\rho_{\text {sea }}\left(T, S^{\prime}, p\right) \beta_{\text {sea }}\left(T, S^{\prime}, p\right)} \mathrm{d} S^{\prime} \\
= & \rho_{\text {sea }}(T, 0, p)+\int_{0}^{S} \rho_{\text {sea }}\left(T, S^{\prime}, p\right) \beta_{\text {sea }}\left(T, S^{\prime}, p\right) f\left(T, S^{\prime}, p\right) \mathrm{d} S^{\prime}
\end{aligned}
$$



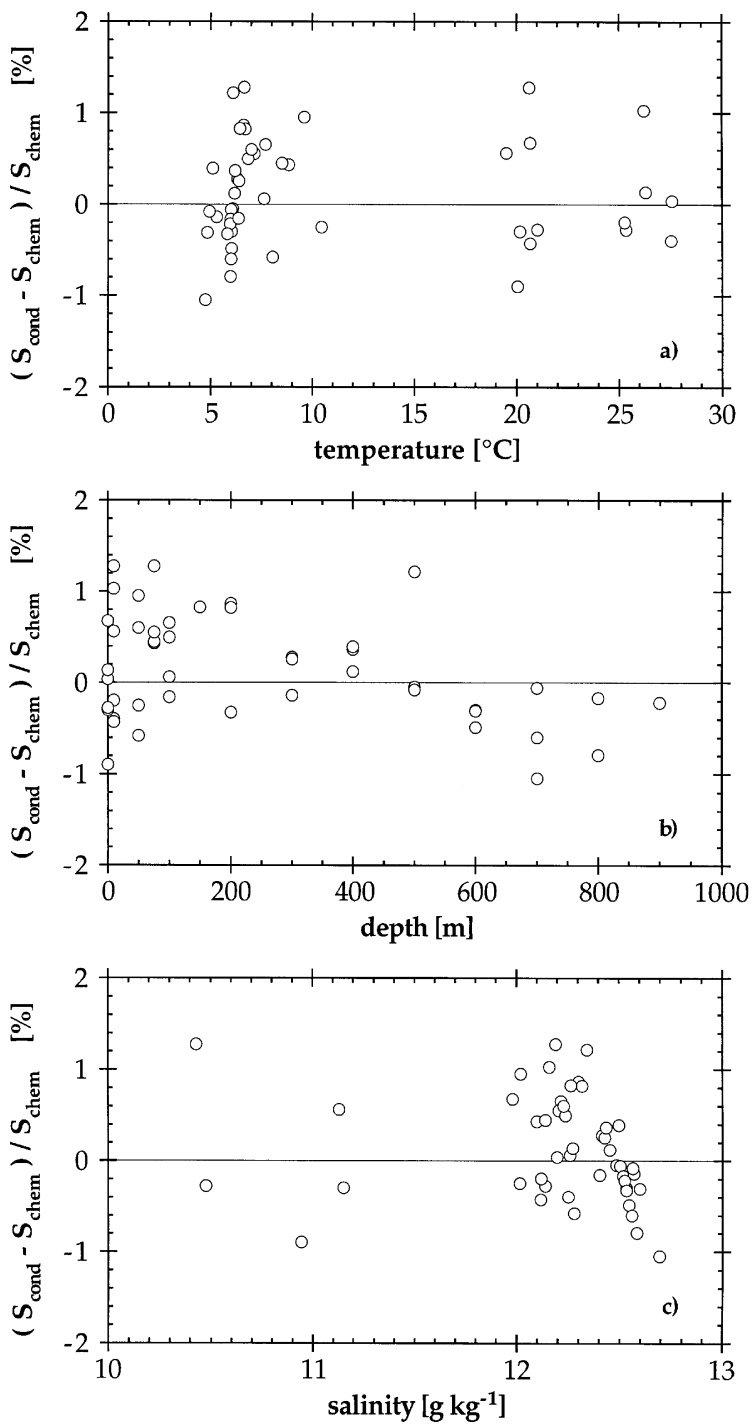

Fig. 3. Comparison of absolute salinity determined from chemistry measurements $\left(S_{\text {chem }}\right)$ and from conductivity $\left(S_{\text {cond }}\right)$. The comparison includes all data from 1995 except for those from the thermocline at 20 to $30 \mathrm{~m}$ depth. At that depth range a small error in depth measured for a water sample may cause large differences in temperature and therefore in salinity if compared to CTD-data, which are based on their own depth information calculated from pressure.

with

$$
f(T, S, p)=\frac{\rho_{\text {solution }}(T, S, p) \beta_{\text {solution }}(T, S, p)}{\rho_{\text {sea }}(T, S, p) \beta_{\text {sea }}(T, S, p)}
$$


$\rho_{\text {solution }}(T, 0, p)=\rho_{\text {sea }}(T, 0, p)$, because at $S=0$ the density must be independent of the ion-composition of the solution. Assuming that the ratio $f$ is independent of the absolute value of salinity one obtains:

$$
\begin{aligned}
\rho_{\text {solution }} & =\rho_{\text {sea }}(T, 0, p)+f(T, p) \int_{0}^{S}\left(\frac{\partial \rho_{\text {sea }}}{\partial S^{\prime}}\right)_{T, p} \mathrm{~d} S^{\prime} \\
& =\rho_{\text {sea }}(T, 0, p)+f(T, p)\left(\rho_{\text {sea }}(T, S, p)-\rho_{\text {sea }}(T, 0, p)\right)
\end{aligned}
$$

because $\rho_{\text {solution }} \approx \rho_{\text {sea }} f$ corresponds, to a good approximation, to the ratio between the haline contraction coefficient of the solution considered to the haline contraction coefficient of standard sea water (see Eq. (6)).

For a solution with ion composition different from standard sea water the haline expansion coefficient can be calculated to a good approximation from apparent molal volumes of binary solutions (Wüest et al., 1996). For the ion composition of Caspian Sea water we obtained a correction factor $f=1.0834$ at $T=25^{\circ} \mathrm{C}, S=12.3 \mathrm{~g} \mathrm{~kg}^{-1}$ and surface pressure $p=0$. According to Eq. (6) the correction factor $f$ for standard sea water must be 1 , independent of salinity, temperature and pressure. In the following we assume the correction factor $f$ to be constant in Caspian Sea water. With this assumption we neglect second order effects, e.g. that the relative change of the total molal volume with temperature may be different in Caspian Sea and in standard sea water.

We assume Caspian Sea water to have a constant relative chemical ion composition, which seems to be justified for most of the water body (see Table 2).

\subsubsection{Comparison with the empirical relations of Millero and Chetirkin (1980)}

Based on six water samples Millero and Chetirkin (1980) determined density $\rho_{\text {MillChe }}\left(\mathrm{Cl}_{\text {mass }}^{-}, T\right)$ as function of chlorinity $\mathrm{Cl}_{\text {mass }}^{-}\left(\mathrm{g} \mathrm{kg}^{-1}\right)$ and temperature for Caspian Sea water by laboratory experiments. In the following we assume that the concentration of halides except for $\mathrm{Cl}^{-}$is negligible in Caspian Sea water, i.e. that chlorinity is equal to the $\mathrm{Cl}^{-}$concentration per mass solution. Then the chlorinity and the density of our samples can be calculated from the empirical equation of state of Millero and Chetirkin:

$$
\mathrm{Cl}_{\text {mass }}^{-}=\frac{\mathrm{Cl}_{\text {volume }}^{-}}{\rho_{\text {MillChe }}\left(T, \mathrm{Cl}_{\text {mass }}^{-}\right)}
$$

where $\mathrm{Cl}_{\text {volume }}^{-}\left(\mathrm{g}^{-1}\right)$ is the chlorine concentration per unit volume. Like Eq. (1), Eq. (8) is an implicit equation for chlorinity which can be solved numerically.

Applying (8) to Caspian Sea water with an ion composition given in Table 2 (column 2) the empirical relations by Millero and Chetirkin predict a chlorinity of $\mathrm{Cl}_{\text {mass }}^{-}=5.197 \mathrm{~g} \mathrm{~kg}^{-1}$ and a salinity of $S=12.32 \mathrm{~g} \mathrm{~kg}^{-1}$, which agrees very well with the $S=12.28 \mathrm{~g} \mathrm{~kg}^{-1}$ derived from our Eqs. (1) and (7).

At surface pressure $(p=0)$ and $T=5^{\circ} \mathrm{C}$ the density of Caspian Sea water with a salinity of $12.20 \mathrm{~g} \mathrm{~kg}^{-1}\left(\mathrm{Cl}^{-}=5.146 \mathrm{~g} \mathrm{~kg}^{-1}\right)$ and of $12.50 \mathrm{~g} \mathrm{~kg}^{-1}\left(\mathrm{Cl}^{-}=5.273 \mathrm{~g}\right.$ $\mathrm{kg}^{-1}$ ) is 1010.465 and $1010.723 \mathrm{~kg} \mathrm{~m}^{-3}$, respectively, using the relations of Millero and Chetirkin (1980). According to our equations the corresponding densities are 
1010.453 and $1010.710 \mathrm{~kg} \mathrm{~m}^{-3}$, respectively, which are systematically smaller than those of Millero and Chetirkin (1980) by only $0.013 \mathrm{~kg} \mathrm{~m}^{-3}$. The $\mathrm{Cl}^{-}$concentrations were calculated by assuming that the ion composition (Table 2) remains constant. At $25^{\circ} \mathrm{C}$ our densities are smaller by $0.075 \mathrm{~kg} \mathrm{~m}^{-3}$ than those of Millero and Chetirkin.

In many hydrodynamic applications the density difference is of central importance rather than the absolute density. According to our equations the density difference in the example above is $0.357 \mathrm{~kg} \mathrm{~m}^{-3}$ in excellent agreement with the $0.358 \mathrm{~kg} \mathrm{~m}^{-3}$, derived from the relations of Millero and Chetirkin (1980). If calculated for the same salinity difference but at $T=25^{\circ} \mathrm{C}$ the density differences also agree well (within $0.002 \mathrm{~kg} \mathrm{~m}^{-3}$ ).

\section{Results}

Surface temperature is largest in the southern basin and decreases towards the north (data from $5 \mathrm{~m}$ depth, Fig. 4a). Potential temperature decreases with increasing depth (Fig. 2a). A very strong thermocline exists at about 20 to $30 \mathrm{~m}$ with a temperature decrease of about $12^{\circ} \mathrm{C}$ within a depth range of $10 \mathrm{~m}$. At same depth the temperature in the deep water region below $200 \mathrm{~m}$ is smaller in the central basin than in the southern basin (Figs. 2 and 5a).
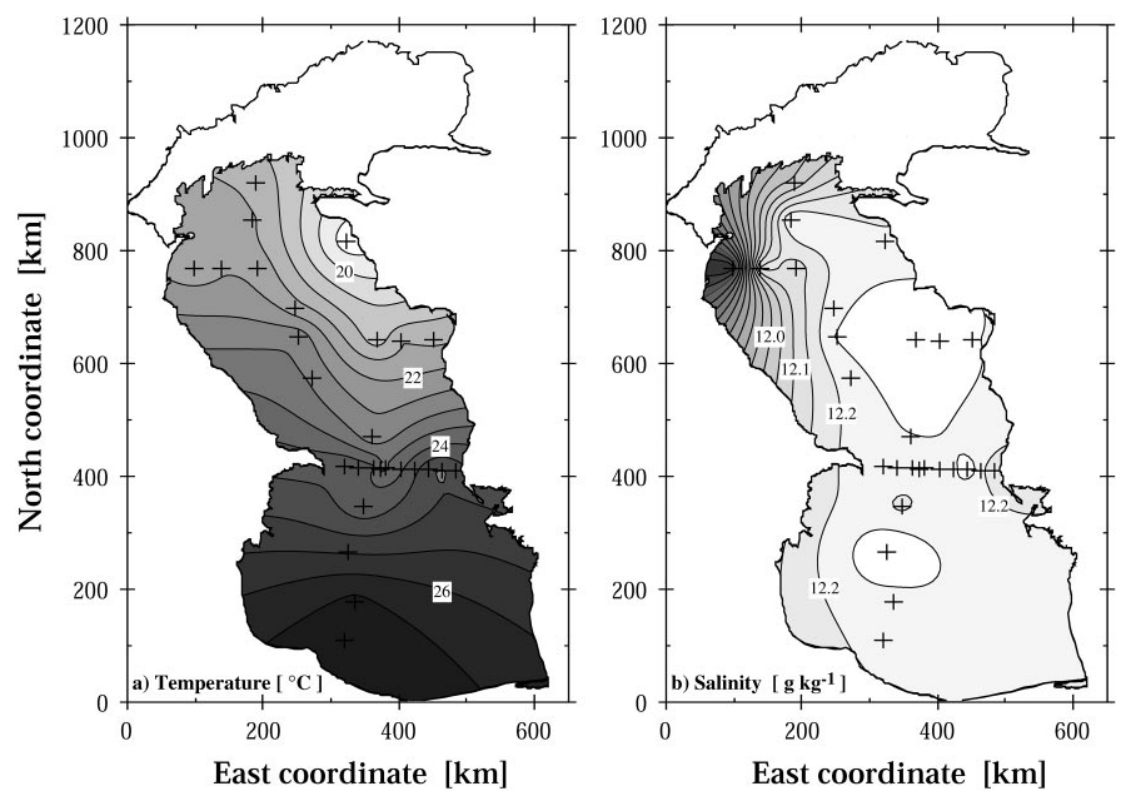

Fig. 4. Horizontal distribution of temperature (a) and salinity (b) near the surface at $5 \mathrm{~m}$ depth. Data were collected in 1996. Symbols mark the sampling stations. 

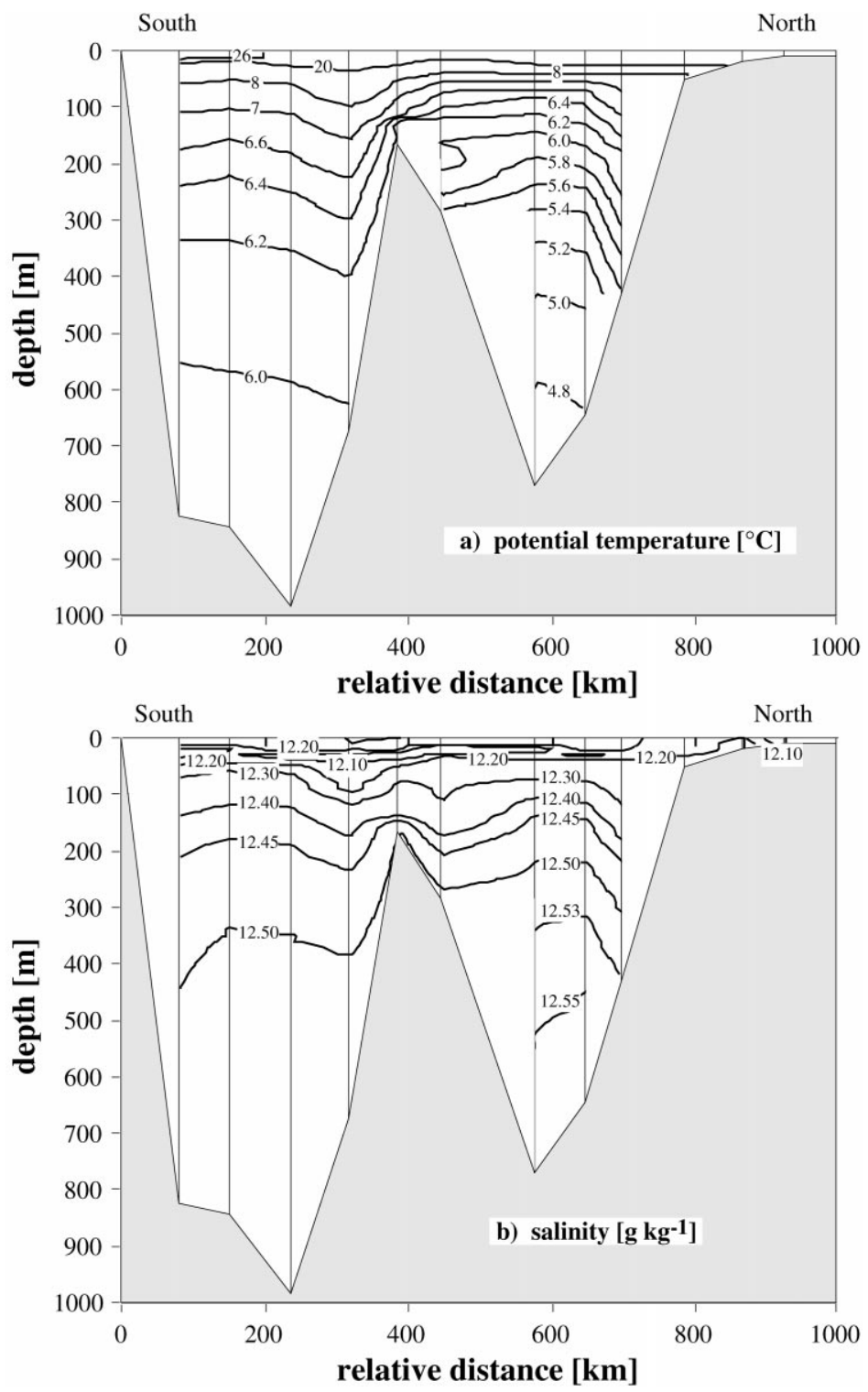

Fig. 5. Two-dimensional isopleths of (a) potential temperature and (b) salinity measured along the thalweg from south (left) to north (right) in September 1996.

In the surface waters salinity is largest in the southern basin and towards the eastern side of the central basin (data from $5 \mathrm{~m}$ depth, Fig. 4b). Salinity decreases from south to north due to the large freshwater inflow into the northern basin (Volga, Ural, Terek). The low salinities towards the western shore in the central basin are caused by 

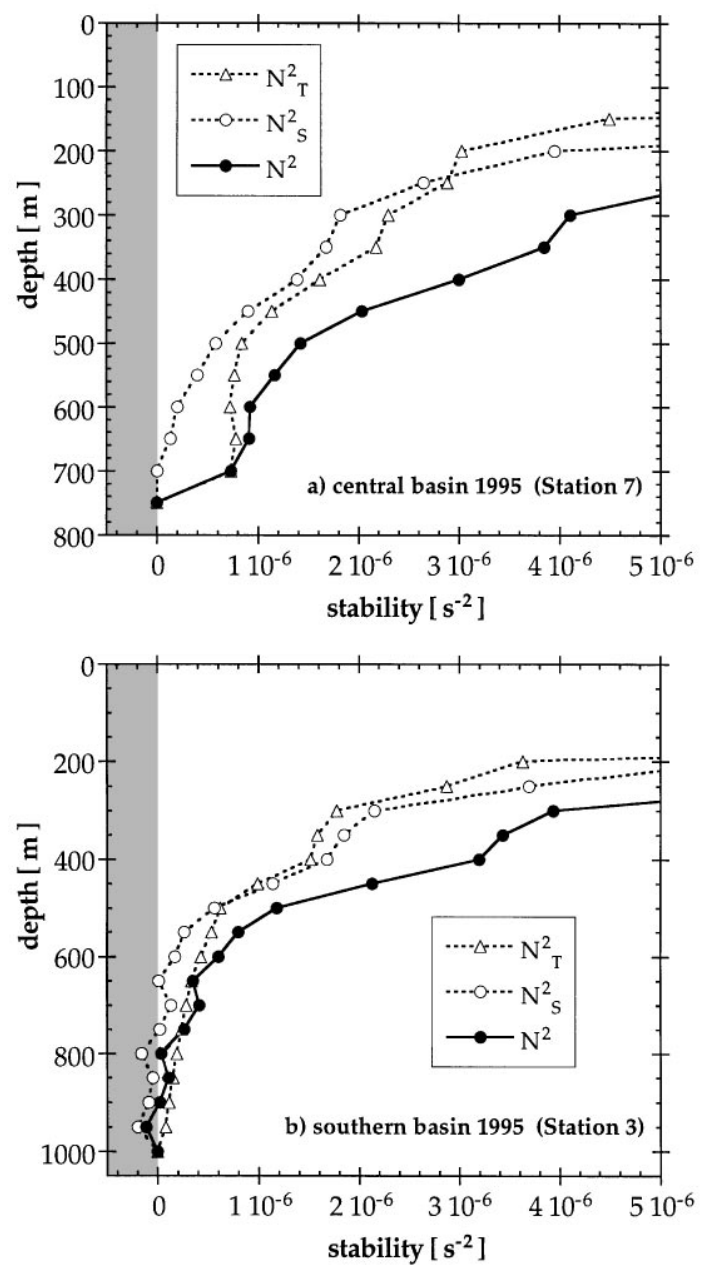

Fig. 6. Brunt Väisälä frequency $N^{2}$, which is a measure of the local stability of the water column, at the deepest station of the central basin (a) and the southern basin (b). $N^{2}$ is the sum of the contribution to stability by the temperature gradient $N_{T}^{2}$ and by the salinity gradient $N_{S}^{2}$ (see Eq. (7)).

the Sulak River. Similar inflows occur in the southern basin, but there sampling was only along the central line. Salinity decreases from the surface region down to about $50 \mathrm{~m}$ (Fig. 2b). Below $50 \mathrm{~m}$ salinity increases, and at $200 \mathrm{~m}$ depth salinity is already larger than at the surface. Maximum salinities are reached close to the bottom. At the same depths below $200 \mathrm{~m}$ salinity is larger in the central basin than in the southern basin (Figs. $2 \mathrm{~b}$ and $5 \mathrm{~b}$ ). In the surface region above $50 \mathrm{~m}$ the horizontal salinity gradient changes and salinity is larger in the southern than in the central basin. 
From temperature and salinity profiles one can calculate the Brunt Väisälä frequency $N^{2}$ (Fig. 6), which is a measure of the stability of a water column:

$$
\begin{aligned}
& N_{T}^{2}=g \alpha\left(\frac{\mathrm{d} T}{\mathrm{~d} z}+\Gamma_{z}\right), \\
& N_{S}^{2}=-g \beta \frac{\mathrm{d} S}{\mathrm{~d} z}, \\
& N^{2}=N_{T}^{2}+N_{S}^{2},
\end{aligned}
$$

where $g$ is the gravitational constant, $\alpha$ the thermal expansion coefficient and $\Gamma_{z}$ the adiabatic lapse rate (e.g. Gill, 1982). $N_{T}^{2}$ and $N_{S}^{2}$ are a measure of the stabilizing effect of the distribution of temperature and of salinity, respectively. In the Caspian Sea $N_{T}^{2}$ and $N_{S}^{2}$ are positive in most regions, i.e. the temperature and the salinity distribution both stabilise the water column. In the deep water region of the central basin the contribution to stability by the temperature gradient is slightly larger than that by the salinity gradient (Fig. 6).

Concentrations of $\mathrm{CFC}-12$ and $\mathrm{CFC}-11$ show a large increase from the surface value at around $10 \mathrm{~m}$ to the next sample at $150 \mathrm{~m}$ depth (Fig. $7 \mathrm{a}$ and b). Below $150 \mathrm{~m}$ depth CFC-12 and CFC-11 concentrations decrease with increasing depth, reaching values well below the surface concentrations. Note that the correction of the CFC-11 concentrations for decomposition in the sample containers (see Section 2.1) accounts for only about 0.2 and $0.1 \mathrm{pmol} \mathrm{kg}^{-1}$ of the concentration in the southern and the central basin, respectively.

Tritium concentrations tend to increase from the southern to the northern basin, where the largest values of the entire Caspian Sea are found (Fig. 7d). In the deep water region the differences in ${ }^{3} \mathrm{H}$ concentration between southern and central basin are about $5 \mathrm{TU}$, while at depths above $300 \mathrm{~m}{ }^{3} \mathrm{H}$ concentrations are approximately the same in the two basins. In the southern basin tritium concentrations decrease with increasing depth (Fig. 7d) except for the deepest samples. In the central basin tritium concentrations from 1995 show a minimum at about $300 \mathrm{~m}$ depth while in 1996 ${ }^{3} \mathrm{H}$ decreased very slightly with increasing depth. ${ }^{3} \mathrm{H}$ concentrations decreased from September 1995 to September 1996.

The ${ }^{3} \mathrm{He}$ concentration originating from tritium decay, ${ }^{3} \mathrm{He}_{\text {tri }}$, increases with increasing depth, with the possible exception of the deepest samples (Fig. 7e). Down to about $300 \mathrm{~m}$ depth ${ }^{3} \mathrm{He}_{\mathrm{tri}}$ values are approximately the same in the southern and the central basin, while below $300 \mathrm{~m}^{3} \mathrm{He}_{\text {tri }}$ is significantly larger in the central than in the southern basin. Details on the definition of ${ }^{3} \mathrm{He}_{\text {tri }}$ are given below.

${ }^{4} \mathrm{He}$ concentrations are larger in the southern than in the central basin (Fig. 2c). Most likely this difference is caused by mud-volcanoes found in the southern basin, which introduce ${ }^{4} \mathrm{He}$ into the water column. Enrichment in crustal helium was found in warm springs on land near Baku.

Oxygen concentrations are largest near the surface (Fig. 2d), where $\mathrm{O}_{2}$ is oversaturated (125-140\% saturation) compared to the hypothetical $\mathrm{O}_{2}$ equilibrium concentration, i.e. to the oxygen in equilibrium with the atmosphere at the salinity and 

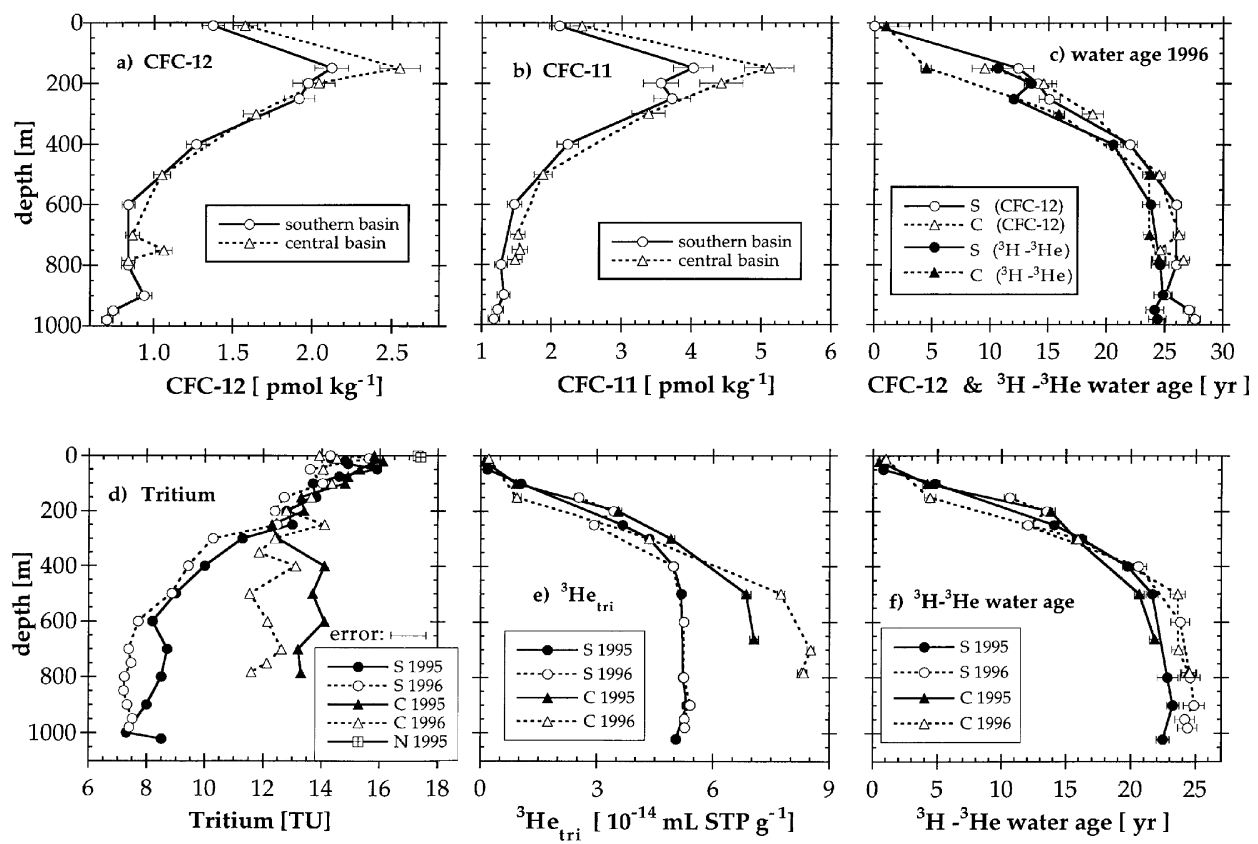

Fig. 7. Concentrations of CFC-12, CFC-11, tritium, tritiogenic ${ }^{3} \mathrm{He}$ and the $\mathrm{CFC}-12$ and the ${ }^{3} \mathrm{H}-{ }^{3} \mathrm{He}$ water age. Data shown are from both cruises (1995 and 1996) and stem from the deepest stations of the southern (S, station 3), the central (C, station 8 in 1995 and station 7 in 1996) and the northern basin (N, station 13). CFC-12 water age and ${ }^{3} \mathrm{H}-{ }^{3} \mathrm{He}$ water age from 1996 are compared in Fig. 7c. In Fig. $7 \mathrm{f}^{3} \mathrm{H}-{ }^{3} \mathrm{He}$ water ages from 1995 are compared to those from 1996.

potential temperature of the sample. The $\mathrm{O}_{2}$ solubility was calculated from Weiss (1970) using an atmospheric pressure of $1.0039 \mathrm{~atm}$. The $\mathrm{O}_{2}$ oversaturation near the water surface most likely is caused by biological production. In samples from 50 to $100 \mathrm{~m}$ depth the $\mathrm{O}_{2}$ concentration closely agrees with the corresponding hypothetical $\mathrm{O}_{2}$ equilibrium concentrations (80-100\% saturation). At the deepest points of the southern and central basin $\mathrm{O}_{2}$ concentrations are strongly undersaturated due to oxygen consumption and reach only about 2 and $3 \mathrm{mg} \mathrm{l}^{-1}$, respectively.

\section{Discussion}

\subsection{Quantification of deep water renewal}

\subsection{1. ${ }^{3} \mathrm{H}^{3} \mathrm{He}$ and $\mathrm{CFC}$ water age}

From the concentrations of transient tracers the deep water renewal rate can be estimated. The combination of ${ }^{3} \mathrm{H}$ and ${ }^{3} \mathrm{He}$ measurements within the same water 
sample allows one to calculate the so called ${ }^{3} \mathrm{H}-{ }^{3} \mathrm{He}$ water age $\tau$ (Torgersen et al., 1977):

$$
\tau=\frac{1}{\lambda} \ln \left(1+\frac{{ }^{3} \mathrm{He}_{\mathrm{tri}}}{{ }^{3} \mathrm{H}}\right)
$$

where $\lambda=0.05599 \mathrm{yr}^{-1}$ (Oliver et al., 1989) and ${ }^{3} \mathrm{He}_{\mathrm{tri}}$ stands for tritiogenic ${ }^{3} \mathrm{He}:{ }^{3} \mathrm{He}_{\text {tri }}={ }^{3} \mathrm{He}_{\text {tot }}-{ }^{3} \mathrm{He}_{\text {equ }}-{ }^{3} \mathrm{He}_{\text {air }}-{ }^{3} \mathrm{He}_{\text {terr }}$ where ${ }^{3} \mathrm{He}_{\text {tot }}$ is the total ${ }^{3} \mathrm{He}$ concentration, ${ }^{3} \mathrm{He}_{\text {equ }}$ is the ${ }^{3} \mathrm{He}$ equilibrium concentration that the water sample would have at the sea surface, ${ }^{3} \mathrm{He}_{\text {air }}$ is the contribution of ${ }^{3} \mathrm{He}$ due to excess air and ${ }^{3} \mathrm{He}_{\mathrm{terr}}$ is the terrigenic ${ }^{3} \mathrm{He}$ concentration, which originates from helium degassing from the earth's crust or mantle. ${ }^{3} \mathrm{He}_{\text {air }}$ is small (Table 4). In the Caspian Sea the contribution of ${ }^{3} \mathrm{He}_{\text {terr }}$ is also negligible compared to the total amount of excess ${ }^{3} \mathrm{He}$, because the excess of terrigenic ${ }^{4} \mathrm{He}$ is only on the order of $10 \%$ with a low ${ }^{3} \mathrm{He} /{ }^{4} \mathrm{He}$ ratio of $6 \times 10^{-8}$. The ratio ${ }^{3} \mathrm{He} /{ }^{4} \mathrm{He}$ of the terrigenic component has been determined from a thermal spring near Baku.

Because the tritiogenic ${ }^{3} \mathrm{He}$ concentration in a given water volume has been produced by tritium decay in the same water volume the ratio of ${ }^{3} \mathrm{He}_{\mathrm{tri}}$ and ${ }^{3} \mathrm{H}$ contains information on the time elapsed since the water sample was last in contact with the atmosphere. This time period is the apparent water age or the ${ }^{3} \mathrm{H}-{ }^{3} \mathrm{He}$ water age. Details on the ${ }^{3} \mathrm{H}-{ }^{3} \mathrm{He}$ method and the procedure to calculate ${ }^{3} \mathrm{He}_{\mathrm{tri}}$ have been described in Aeschbach-Hertig et al. (1996). The atmospheric equilibrium concentration of ${ }^{3} \mathrm{He}$ was calculated using $\mathrm{He}$ solubilities given by Weiss (1971) and the fractionation factor between ${ }^{4} \mathrm{He}$ and ${ }^{3} \mathrm{He}$ given by Benson and Krause (1980).

${ }^{3} \mathrm{H}-{ }^{3} \mathrm{He}$ water age increases with increasing water depth. In 1995 and in 1996 the apparent water age at any given depth below $200 \mathrm{~m}$ was approximately the same in the southern and central basin (Fig. 7f). This is in contrast to the concentration of ${ }^{3} \mathrm{H}$ and the concentration of ${ }^{3} \mathrm{He}$, which differ quite substantially between basins (Fig. 7d and e). From 1995 to 1996 the ${ }^{3} \mathrm{H}-{ }^{3} \mathrm{He}$ water ages in the deep water of the southern and the central basin increased by at least one year, which suggests that no deep water renewal occurred within this time period. Unfortunately, the time period of one year between measurements is not much larger than the errors of the ${ }^{3} \mathrm{H}-{ }^{3} \mathrm{He}$ water ages.

An apparent water age can also be determined from the concentration of chlorofluorocarbons. The solubility of CFC-11 or CFC-12 at the potential temperature and the salinity of the water sample combined with the historic atmospheric partial pressures of CFC-11 or CFC-12 gives the "historic" atmospheric equilibrium concentrations for the particular sample. The historic atmospheric partial pressures of CFCs are strongly time dependent, because significant production of CFCs, which are of anthropogenic origin, began in the 1930s (Busenberg and Plummer, 1992) and increased rapidly until the early 1990s. Comparing the CFC concentration measured in the sample with the "historic" equilibrium concentrations provides the apparent date of equilibration. Alternatively, the apparent date of equilibration can be obtained by comparing the equilibrium partial pressure calculated for each sample with the historic partial pressure. The two methods provide equivalent results. The elapsed 
time between the apparent equilibration date and the sampling date gives the CFC apparent water age. Note that in some previous investigations (e.g. Weiss et al., 1991) CFC-12 data have been altered prior to the calculation of CFC-12 apparent water age to achieve a zero age at a prescribed location. We have not included such a correction because it is already an interpretation of apparent water age in terms of mixing (see below).

The historic equilibrium concentrations were calculated by using the solubilities published by Warner and Weiss (1985) at an atmospheric pressure of $1.0039 \mathrm{~atm}$ in combination with the atmospheric CFC concentrations for the northern hemisphere published by Elkins et al. (1993), Katz et al. (1995) and Montzka et al. (1996).

Note that the "historic" equilibrium concentrations of CFCs are different for each water sample because the solubility of CFCs strongly depends on water temperature. Thus, the calculation of CFC-11 or CFC-12 water age is reliable only if the temperature associated with a water sample corresponds to the temperature at which the water sample was in equilibrium with the atmosphere (equilibrium temperature). To test this assumption we calculated the equilibrium temperature from noble-gas measurements for samples collected in different depths at the deepest stations in the southern and central basin, and at the stations A2 and A3 (Table 4). We assumed that at the time when the water was at the surface the noble gases $\mathrm{Ne}, \mathrm{Ar}, \mathrm{Kr}$ and $\mathrm{Xe}$ were in equilibrium with the atmosphere, and we additionally allowed for an excess in the nobles gas concentration due to dissolution of air bubbles. Equilibrium concentrations are based on the empirical relations of Weiss (1970,1971), Clever (1979) and Smith and Kennedy (1983). A detailed discussion of how to obtain equilibrium temperatures and excess air from noble gas concentrations is given in AeschbachHertig et al. (1999).

Under the assumptions above we obtained equilibrium temperatures that are in excellent agreement with the potential temperatures obtained from CTD-measurements at the corresponding locations (Table 4). This suggests that the potential temperatures observed in the water column reliably represent the equilibrium temperatures. The excess air calculated for our samples ranges between $1.5 \%$ and $3.9 \% \mathrm{Ne}$ excess relative to atmospheric equilibrium and is in good agreement with data on excess air in the oceans, which is caused by wave related air-bubble production (Bieri, 1971).

Apparent water ages determined from CFC-12 and from ${ }^{3} \mathrm{H}-{ }^{3} \mathrm{He}$ have a very similar vertical structure (Fig. 7c). As for the ${ }^{3} \mathrm{H}-{ }^{3} \mathrm{He}$ water age the $\mathrm{CFC}-12$ water age is the same in the southern and the central basin at equivalent depths. The concentrations of the tracers on which the two methods for the calculation of water age are based differ however in their behaviour in the two basins, i.e. at the same depth ${ }^{3} \mathrm{H}$ and ${ }^{3} \mathrm{He}$ are much larger in the central than in the southern basin while CFC-12 concentrations are the same in both basins. The close qualitative agreement of apparent water ages obtained from two methodologically independent methods supports the reliability of conclusions drawn from apparent water ages in the Caspian Sea.

The CFC-12 water ages are somewhat larger than the ${ }^{3} \mathrm{H}-{ }^{3} \mathrm{He}$ water ages obtained for samples of the same year (Fig. 7c). A similar difference in apparent water age has also been observed in Lake Baikal, Siberia (Peeters et al., 1997). 


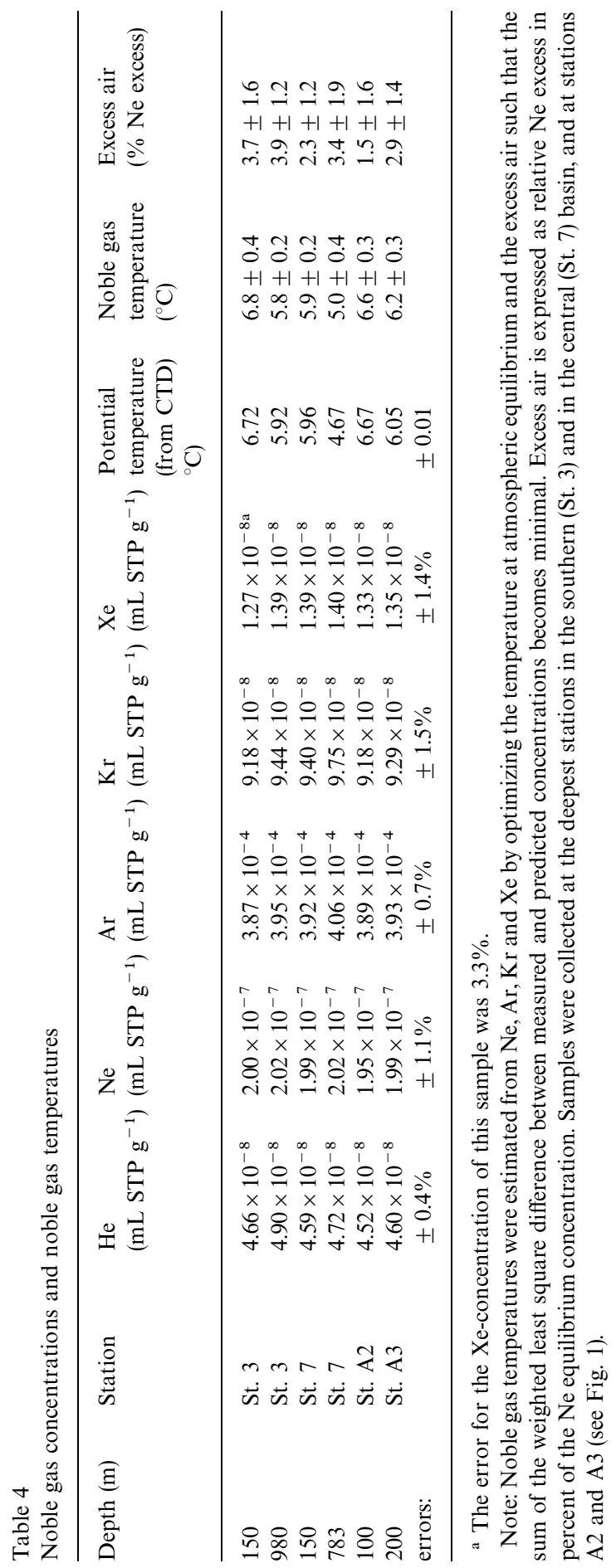


The apparent water ages from the surface layer (uppermost $20 \mathrm{~m}$ ) are close to zero indicating that the CFC-12 and the ${ }^{3} \mathrm{He}$ concentrations are almost in equilibrium with the atmosphere. Actually, the CFC-12 concentration of the $20 \mathrm{~m}$ sample from the southern basin is slightly oversaturated (saturation of $102.6 \% \pm 5 \%$ ) compared to the present day atmospheric equilibrium $\mathrm{CFC}-12$ concentration. Within the experimental error the CFC-12 concentration is compatible with a CFC-12 water age ranging from 0 to $3 \mathrm{yr}$. The surface sample from the central basin is saturated by $106.8 \% \pm 5 \%$ and an apparent water age cannot be assigned.

The ${ }^{3} \mathrm{H}-{ }^{3} \mathrm{He}$ and the CFC-12 water ages in the deeper part of the seasonal mixed layer (samples from $150 \mathrm{~m}$ depth) are significantly larger than one year indicating that ${ }^{3} \mathrm{He}$ is oversaturated and $\mathrm{CFC}-12$ is undersaturated compared to the atmospheric equilibrium concentration at the sample's temperature and salinity. The oversaturation of ${ }^{3} \mathrm{He}$ at $150 \mathrm{~m}$ depth is partly due to tritium decay and partly due to deep water exchange, which introduces water with high ${ }^{3} \mathrm{He}$ concentration into the seasonal mixed layer (Fig. 7e). Exchange of deep water, which contains low CFC-12 concentrations, also explains the fact that the $\mathrm{CFC}-12$ concentration in the seasonal mixed layer at $150 \mathrm{~m}$ depth lags behind the actual atmospheric equilibrium concentration by more than a year. In addition, mixing of warm water from the surface layer with cold water from the deeper seasonal mixed layer might also lead to undersaturation of CFC-12 due to the temperature dependence of the solubility of CFC-12. Note, however, that the water in the surface layer must cool down significantly to generate seasonal mixing. Because the surface layer is very shallow, CFC-12 concentrations will increase substantially before the onset of seasonal mixing due to gas exchange with the atmosphere and the higher solubility of CFC-12 at lower temperatures.

Apparent water ages determined from CFC-11 concentrations are slightly larger by about 1 to $3 \mathrm{yr}$ than those determined from CFC-12 concentrations, except for the surface samples, which have unrealistically high $\mathrm{CFC}-11$ water ages. In general, the CFC-11 water ages are less reliable than the CFC-12 water ages because the experimental error of the CFC- 11 concentrations is about $\pm 7 \%$, the correction for CFC-11 decomposition in the sample containers adds additional uncertainty, and the partial pressure of CFC-11 in the atmosphere did not change monotonically between 1991 and 1996. However, like the CFC-12 and the ${ }^{3} \mathrm{H}-{ }^{3} \mathrm{He}$ water ages the CFC-11 water ages in the deep water agree very well between basins at same depth supporting the reliability of the conclusions drawn from $\mathrm{CFC}-12$ and ${ }^{3} \mathrm{H}-{ }^{3} \mathrm{He}$ water ages.

\subsubsection{Deep water renewal times}

The difference in the volume-weighted mean apparent water age (hereafter termed mean water age) between water from the top $200 \mathrm{~m}$ (seasonal mixed layer) and the deep water region below $200 \mathrm{~m}$ is a measure of the mean time required for the exchange of the deep water by water from the seasonal mixed layer. The mean deep water renewal time in 1996 is about $15 \pm 1 \mathrm{yr}$ in the central and in the southern basin and does not change significantly if its calculation is based on CFC-12 water age instead of on ${ }^{3} \mathrm{H}-{ }^{3} \mathrm{He}$ water age (Table 5). Mean exchange velocities and the mean water volume exchanged annually were calculated from the mean deep water residence times and are summarised in Table 6. 


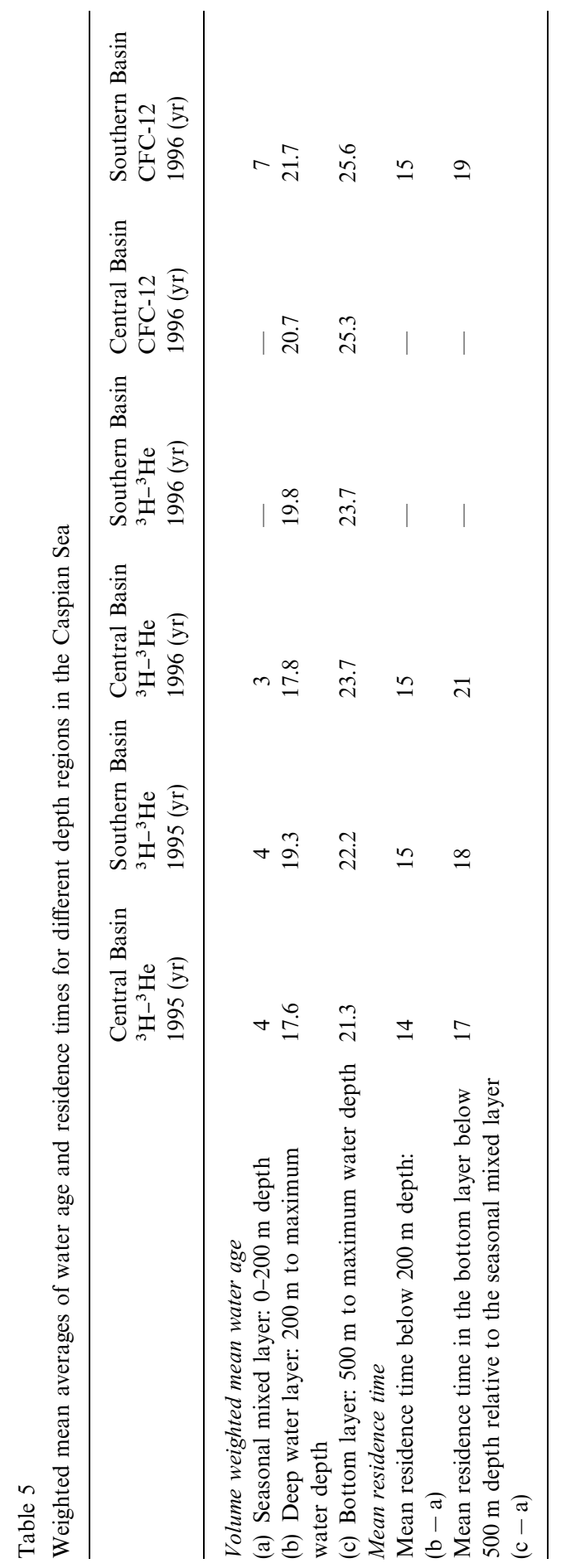


Table 6

Renewal of the deep water below $200 \mathrm{~m}$ depth by surface water from above $200 \mathrm{~m}$ depth

\begin{tabular}{lll}
\hline & Central Basin & Southern Basin \\
\hline Mean residence time below 200 m depth & $15 \mathrm{yr}$ & $15 \mathrm{yr}$ \\
Mean annual exchange rate & $6.7 \%$ & $6.7 \%$ \\
Mean exchange velocity & $17 \mathrm{~m} \mathrm{yr}^{-1}$ & $31 \mathrm{mr}^{-1}$ \\
Mean volume exchanged annually & $770 \mathrm{~km}^{3} \mathrm{yr}-1$ & $2220 \mathrm{~km}^{3} \mathrm{yr}^{-1}$ \\
Typical error of these estimates & $7 \%$ & $7 \%$ \\
\hline
\end{tabular}

The calculation above of the mean renewal time assumes that the mean water age of the seasonal mixed layer was the same at all times. In the literature mixing times were derived by calculating apparent water ages from CFC-12 concentrations, which were multiplied by a fixed factor (e.g. Weiss et al. (1991) used a factor of 1.22 for Lake Baikal, which closely corresponds to a shift of apparent water age of $5 \mathrm{yr}$ ). This procedure was employed to produce zero water age within the seasonal mixed layer and assumes that at all times the CFC-12 concentration in the seasonal mixed layer was undersaturated by the same ratio relative to the atmospheric equilibrium concentration.

Note that the undersaturation of CFCs in the seasonal mixed layer results from the interplay between deep water mixing, limited gas exchange with the atmosphere and rising atmospheric $\mathrm{CFC}$ concentrations. For time periods during which the atmospheric partial pressure of CFC-12 increased linearly (e.g. 1980 to 1990) it is reasonable to assume that the CFC-12 concentration in the seasonal mixed layer lagged behind the atmospheric equilibrium concentration at a constant ratio. However, if the atmospheric CFC-12 concentration increases at a slower rate, as is the case since 1990, the CFC-12 concentration in the seasonal mixed layer should agree more closely to the atmospheric equilibrium value, i.e. the undersaturation should be smaller. Correspondingly undersaturations should be larger in time periods when atmospheric concentrations increase more rapidly (e.g. in the 1970s).

Assuming a constant CFC-12 water age in the seasonal mixed layer of, e.g. $5 \mathrm{yr}$ corresponds to an undersaturation of $22 \%$ in 1983 and of $21 \%$ in 1990 , i.e. is essentially equivalent to assuming a constant CFC-12 undersaturation of about $21 \%$ for the time period between 1983 and 1990. Because of the slower increase of atmospheric CFC-12 concentration since 1990 the same CFC-12 water age corresponds to a smaller undersaturation, e.g. $5 \mathrm{yr}$ corresponds to $10 \%$ undersaturation in 1995. Thus, the residence time calculated from differences in CFC-12 water age accounts, at least to some extent, for the change in the rate of increase of the atmospheric CFC-12 concentrations and interprets the CFC-12 undersaturation in the seasonal mixed layer more realistically as a result of mixing than a constant ratio of undersaturation.

Preferably, the mean water age in the seasonal mixed layer should be calculated from tracer data collected during seasonal mixing. However, since such data is not available mean water ages in the seasonal mixed layer were estimated using the 
apparent water ages determined from the tracer data collected during our expeditions in September. Because sources, boundary conditions and concentration distributions of ${ }^{3} \mathrm{He}$ and ${ }^{3} \mathrm{H}$ are very different from those of $\mathrm{CFC}-12$ the good agreement of the deep water renewal times derived from the difference in ${ }^{3} \mathrm{H}-{ }^{3} \mathrm{He}$ and $\mathrm{CFC}-12$ water ages supports the reliabilty of the exchange rates given in Table 6 .

\subsubsection{Oxygen depletion and flux of ${ }^{4} \mathrm{He}$}

Apparent water ages can be employed to estimate oxygen depletion rates by assuming that oxygen has been consumed during a time period that corresponds to the difference in apparent water age. Comparison of oxygen concentration and apparent water age from water samples taken from 100 and $700 \mathrm{~m}$ depth for the central and 100 and $1000 \mathrm{~m}$ depth for the southern basin suggests that oxygen levels have decreased from about 9.0 to about $3.0 \mathrm{mg} 1^{-1}$ over $17.6 \mathrm{yr}$ in the central and from about $9.2 \mathrm{mg}^{-1}$ to about $2.2 \mathrm{mg}^{-1}$ over about $17.7 \mathrm{yr}$ in the southern basin. The corresponding mean oxygen depletion rate for the deep water region of the Caspian Sea is on the order of $0.35 \mathrm{mg}^{-1} \mathrm{yr}^{-1}$.

Similarly apparent water ages can also be employed to estimate the flux of ${ }^{4} \mathrm{He}$ from underground (Aeschbach-Hertig et al., 1996; Hohmann et al., 1998) by assuming that terrigenic ${ }^{4} \mathrm{He}$ accumulates at a constant rate in the water column and that the accumulation time corresponds to differences in apparent water age. The terrigenic ${ }^{4} \mathrm{He}$ component can be obtained from the measured ${ }^{4} \mathrm{He}$ concentrations by subtracting the atmospheric equilibrium concentration of ${ }^{4} \mathrm{He}$ and the atmospheric ${ }^{4} \mathrm{He}$ excess due to direct input of air (e.g. by air bubbles). The latter can be determined from excess in $\mathrm{Ne}$ concentrations, i.e. the difference between measured $\mathrm{Ne}$ and $\mathrm{Ne}$ in equilibrium with the atmosphere (for details on determining ${ }^{4} \mathrm{He}$ flux from the underground see Aeschbach-Hertig (1994)).

According to the data from 1995 and from 1996 the terrigenic ${ }^{4} \mathrm{He}$ concentration in the southern basin of the Caspian Sea increases with the ${ }^{3} \mathrm{H}-{ }^{3} \mathrm{He}$ water age at a rate of about $1.5 \times 10^{-10} \mathrm{~mL} \mathrm{STP} \mathrm{g}^{-1} \mathrm{yr}^{-1}$. From this rate and the mean water depth of the southern basin follows a ${ }^{4} \mathrm{He}$ flux on the order $4.5 \times 10^{10}$ atoms $\mathrm{m}^{-2} \mathrm{~s}^{-1}$. This ${ }^{4} \mathrm{He}$ flux agrees well with the average ${ }^{4} \mathrm{He}$ flux of about $3 \times 10^{10}$ atoms $\mathrm{m}^{-2} \mathrm{~s}^{-1}$ from the continental crust (O'Nions and Oxburgh, 1983) and with the ${ }^{4} \mathrm{He}$ flux derived from ${ }^{4} \mathrm{He}$ accumulation in Lake Lugano (Aeschbach-Hertig, 1994) and is on the same order as the ${ }^{4} \mathrm{He}$ flux found in Lake Lucern (Aeschbach-Hertig et al., 1996) and in the southern and central basin of Lake Baikal (Hohmann et al., 1998).

\subsection{Processes causing deep water renewal}

Temperatures in the deep water of the Caspian Sea are well below the annual mean temperature of the seasonal mixed layer, and in the southern basin they are even below the annual minimum of the monthly surface temperatures. This suggests that vertical transport is not accomplished by turbulent diffusion alone but that large-scale convection also plays a role in the distribution of heat and dissolved solids. In the following, we discuss whether in the Caspian Sea convective transport could be initiated by buoyancy effects generated by e.g. seasonal cooling. 
The water column was stably stratified during our cruises in late summer (Fig. 6), suggesting that vertical convection is suppressed. However, the temperature and the salinity distribution shown in Fig. 5 indicate that convection takes place near the sill separating the central and southern basin. At 100 to $150 \mathrm{~m}$ depth water from the central basin has a larger potential density than water from the southern basin, because central basin water has a lower temperature and approximately the same salinity as water from the southern basin. Horizontal transport of water from the central basin across the sill towards south leads to convection within the southern basin. Driven by its buoyancy central basin water from $150 \mathrm{~m}$ depth sinks to about $400 \mathrm{~m}$ in the southern basin (Fig. 5).

In principle the buoyancy of central basin water from $200 \mathrm{~m}$ water depth would be sufficient to cause convection down to the bottom of the southern basin (Fig. 8). The grey regions in Fig. 8 were calculated as follows: the in situ density of a water parcel with a hypothetical potential temperature $\theta$ and salinity $S$ was compared to the in situ density calculated from a measured $\theta-S$ profile. The grey regions in Fig. 8 mark combinations of $\theta$ and $S$ that would result in in situ densities for the water parcel that are larger at all depth compared to the in-situ density calculated for the $\theta-S$ profiles from station 3 (light grey) and station 7 (dark grey). The symbols in Fig. 8 represent values of $\theta$ and $S$ measured with the CTD-probe within the top $200 \mathrm{~m}$ at stations 3 (open circles), 5 (triangles) and 7 (solid circles).

According to Fig. 8 water from the top $200 \mathrm{~m}$ in the central basin (solid circles) would propagate to maximum depth if transported to station 3, i.e. to the central station in the southern basin. Thereby, we assume that no entrainment occurs, i.e. that water parcels keep their $\theta$ and $S$ characteristics. Water from the sill (triangles, station 5), however, does not reach the light grey region, i.e. its buoyancy is not sufficient to reach maximum water depths in the southern basin. In the central basin deep-water convection can occur only if surface water is cooled substantially or the salinity of the surface water is significantly increased (Fig. 8b).

The surface temperature in the southern basin attains its annual minimum of about $7^{\circ} \mathrm{C}$ in February, when the basin-mean surface temperature is about $9^{\circ} \mathrm{C}(\mathrm{Kosarev}$ and Tuhylkin, 1995). According to Fig. $8 \mathrm{~b}$ the increase in density due to seasonal cooling in the southern basin is not sufficient to cause convection to the deepest region within the basin.

In the central basin the basin-mean temperature reaches an annual minimum of about $4.7^{\circ} \mathrm{C}$ in January (dashed line in Fig. 8b). Thus, seasonal cooling down to the basin-mean temperature cannot result in deep-water exchange down to the deepest region of the central basin (Fig. 8b). However, in the central basin convective transport might be generated near the basin boundaries, where surface water temperatures can decrease to $0^{\circ} \mathrm{C}$ near the ice shield, which is present during the winter months. In addition, salinities in regions near the lake boundaries and in particular near the east shore of the Caspian Sea are significantly higher than the basin average salinity at the same depth (Kosarev and Yablonskaya, 1994).

Salinities are lowest at about 30 to $50 \mathrm{~m}$ water depth (Fig. 2). Therefore, the mean salinity within the top $200 \mathrm{~m}$ will be lower during seasonal mixing than the salinity at $200 \mathrm{~m}$ depth and possibly even lower than the surface salinities measured during our 

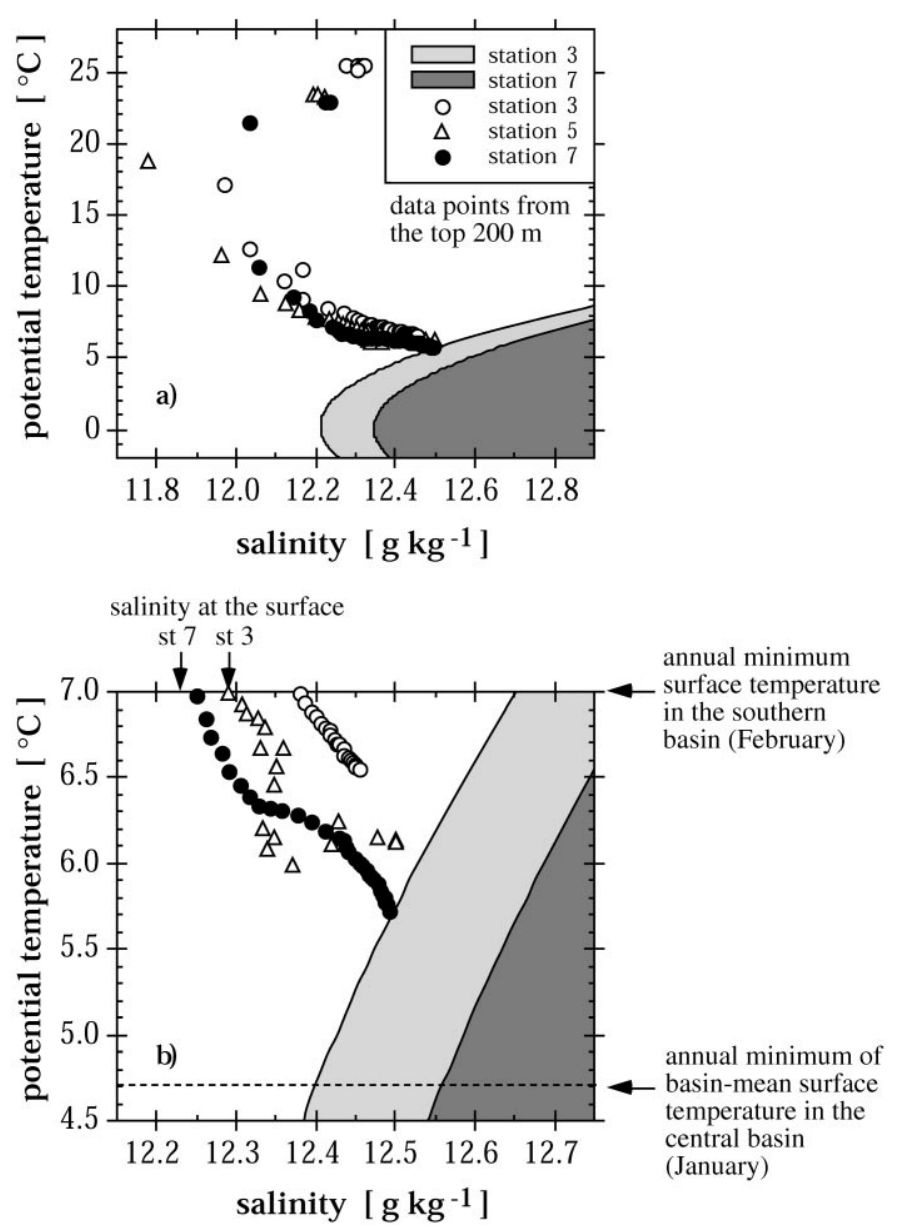

Fig. 8. Convection in the central and in the southern basin. Water parcels characterised by combinations of potential temperature $\theta$ and salinity $S$ marked in grey have, at any depth, an in situ density that is larger than the density of the water at station 3 (light grey region) and station 7 (dark grey region), respectively. I.e., a water parcel with such a $\theta-S$ characteristic can sink down to the bottom of the corresponding profile driven by its buoyancy. The symbols show the $\theta-S$ characteristic of the water from the top $200 \mathrm{~m}$ at station 3 (open circles) station 5 (triangles) and station 7 (solid circles) as measured in 1996.

cruises in September. The salinity minimum at about 30 to $50 \mathrm{~m}$ is probably caused by river inflows having lower salinity and lower temperature than the surface water of the lake. Driven by buoyancy the river water intrudes down to a level in the thermocline at which it has the same density as the ambient Caspian Sea water.

Convection could also be generated by an increased load of suspended particles in the water as is the case for river inflows. River water, however, has a much lower salinity than Caspian Sea water so that the load of suspended particles must be substantial for convection to occur. Most of the major rivers enter the northern basin, 
and by the time the riverine water reaches the central basin sedimentation has already reduced the load of suspended particles. Convection driven by suspended particles might occur especially during floods near the mouth of the Kura River, which is the second largest inflow into the Caspian Sea and discharges directly into the southern basin.

\subsection{Two scenarios for deep water renewal}

We suggest two possible scenarios that can lead to deep water renewal that would be sufficiently fast to be in accordance with the tracer data and the deep water renewal times determined from the experimental data.

Assuming that deep water is exchanged by surface water on an annual basis, vertical transport by convection in the central basin requires processes that increase salinity during times at which surface temperatures are low. Therefore, ice formation in the northern part of the central basin, especially during cold winters, might play an important role in deep water renewal (suggested also by Kosarev and Yablonskaya, 1994).

The general circulation in the Caspian Sea is as follows (Kosarev and Yablonskaya, 1994): River water entering the Caspian Sea mainly in the north (e.g. Emba, Ural, Volga, Terek) and along the western shore (e.g. Samur, Sulak, Kura) is transported along the western shore to the southern basin and from there northwards again along the eastern shore. During transport evaporation increases the salt content of the surface water resulting in relatively warm water with a large salinity near the east shore. In late fall and winter this water with high salt content moving northwards eventually reaches the ice boundary in the northern part of the central basin. Because freezing of the water increases the salinity in the water phase and water temperature is close to zero, the density of the surface water might become sufficiently large that convection can take place close to the boundary of the ice cover in the central basin. In the southern basin convection is caused by cold central basin water propagating across the sill separating the central from the southern basin.

According to this scenario salinity should be larger and temperature smaller in the central than in the southern basin, which agrees with observation. The higher concentrations of ${ }^{3} \mathrm{H}$ and ${ }^{3} \mathrm{He}_{\text {tri }}$ in the central basin compared to those in the southern basin however cannot easily be explained. The most severe difficulty for this scenario is to explain the very similar water ages at the same depths in the southern and central basin and the close agreement of deep water renewal rates between the two basins. In order to generate the same residence time in the deep water region below $200 \mathrm{~m}$ of the basins the vertical transport of water must be 3 times larger in the southern than in the central basin (Table 6).

The second scenario we would like to suggest assumes rare large-scale convective mixing events that are followed by long periods with very little mixing mainly due to turbulent diffusion. A major mixing event occurred in 1976, which caused oxygen concentrations to reach 9.6 to $9.9 \mathrm{mg}^{-1}$ (about $80 \% \quad \mathrm{O}_{2}$-saturation assuming $T=4^{\circ} \mathrm{C}$ and $S=12.5 \mathrm{~g} \mathrm{~kg}^{-1}$ ) in the deep water of the central basin (Kosarev and Yablonskaya, 1994). Today, comparable oxygen concentrations can be found only in the surface waters above $100 \mathrm{~m}$ ! 
Since 1978 water levels in the Caspian Sea rose by almost $3 \mathrm{~m}$. This rapid rise in sea level is caused by an increase in riverine inflow of freshwater, which reduces the salinity of the surface water. Consequently, the probability for buoyancy driven vertical transport of surface water has decreased since the water level began to rise.

The difference in the volume weighted mean water age between water from the upper $200 \mathrm{~m}$ and water in the deepest regions below $500 \mathrm{~m}$ was 17 and $18 \mathrm{yr}$ in the central and southern basin, respectively, according to the data collected in 1995, and was 21 and $19 \mathrm{yr}$ in the central and southern basin, respectively, according to the data collected in 1996 (Table 5). Allowing for an error of about $1 \mathrm{yr}$ these estimates are in excellent agreement with a possible major mixing event in 1976 followed by a period of very little mixing. The increase in water age from 1995 to 1996 indicates that no significant deep water exchange occurred between 1995 and 1996.

The same conclusion can be reached from the argument that a major mixing event should result in a similar degree of saturation for CFC-12 and dissolved oxygen in the deep water. The CFC-12 concentrations observed today in the deep water below $500 \mathrm{~m}$ typically are 0.8 to $0.9 \mathrm{pmol} \mathrm{kg}^{-1}$ in the southern and 0.9 to $1.0 \mathrm{pmol} \mathrm{kg}^{-1}$ in the central basin. These CFC-12 concentrations correspond to $53-63 \%$ of the atmospheric equilibrium concentration in 1976 (assuming that the deep water temperatures were the same as today) and to a CFC-12 water age of 7-5 yr in 1976. Because the major mixing event in 1976 caused dissolved oxygen concentrations to reach $80 \%$ of the atmospheric equilibrium concentration in the deep water (Kosarev and Yablonskaya, 1994) it seems reasonable that the same mixing event resulted in CFC-12 concentrations of 53-63\% atmospheric equilibrium saturation in 1976. Therefore, the CFC-12 concentrations below $500 \mathrm{~m}$ observed today could be entirely the result of this mixing event. Because any consecutive vertical mixing would have led to a net downward flux of CFC-12 and thus to an increase in CFC-12 concentration, the deep water below $500 \mathrm{~m}$ depth most likely has not been significantly affected by mixing since 1976.

In the deep water regions of the southern and central basins, the water ages are the same at equivalent depths (Fig. 7c). This experimental observation is consistent with a mixing scenario that assumes that the vertical distribution of tracers is mainly the result of a major mixing event affecting the entire deep-water region of the Caspian Sea. A major mixing event in 1976 could also explain the horizontally inhomogeneous distribution of tritium. Inflow from the Volga River and the exchange of water vapor are the major sources of ${ }^{3} \mathrm{H}$ in the Caspian Sea. The Volga River discharging into the northern basin induces a ${ }^{3} \mathrm{H}$ concentration gradient from north to south that must have been particularly large in the 1970 s shortly after the ${ }^{3} \mathrm{H}$ concentration in precipitation reached its maximum. Because of the horizontal gradient in ${ }^{3} \mathrm{H}$ concentration and the comparatively small volume of the deep water in the central basin, a major vertical exchange event in 1976 should have resulted in higher ${ }^{3} \mathrm{H}$ concentrations in the central basin than in the southern basin. If, after the large scale mixing event, vertical exchange is small, horizontal ${ }^{3} \mathrm{H}$ gradients in the top $200 \mathrm{~m}$ will be reduced by horizontal mixing resulting in the horizontally homogeneous ${ }^{3} \mathrm{H}$ observed.

For CFC's the major source is gas exchange with the atmosphere and thus CFC input into the Caspian Sea is connected to the surface area rather than to inflows. 
Consequently horizontal differences in $\mathrm{CFC}$ concentrations must have been small at all times. Therefore, the observed agreement between CFC concentrations in central and southern basin at the same depths is consistent with both scenarios.

According to Kosarev and Yablonskaya (1994) (citing S.V. Bruyevich (1934)) deep water renewal must have been very small in the 1930s. At this time very little oxygen $\left(<1.5 \mathrm{ml} \mathrm{g}^{-1}\right)$ but considerable amounts of $\mathrm{H}_{2} \mathrm{~S}$ were present in the deep water of the Caspian Sea. The decrease in sea level began in 1940. As a consequence surface water salinity most likely increased, enhancing the probability for deep water convection.

Although a scenario assuming a large vertical mixing event in 1976 followed by very little vertical mixing since then is consistent with ${ }^{3} \mathrm{H}$ data, water ages and the deep water oxygen concentrations reported for 1976, several questions remain. It is not clear whether in 1976 large scale mixing occurred in both basins and not only in the central basin because Kosarev and Yablonskaya (1994) only provide information on dissolved oxygen for the central basin. In addition Kosarev and Yablonskaya (1994) reported for 1986 low oxygen concentrations of 1.9 and $2.8 \mathrm{mg}^{-1}$ in the central and southern basin, respectively. This suggests that at least some vertical mixing must have occurred since 1986 transporting oxygen to the deep water region.

\section{Conclusions}

The concentrations of CFCs, the CFC-12 water ages and the ${ }^{3} \mathrm{H}-{ }^{3} \mathrm{He}$ water ages from the central basin of the Caspian Sea agree very well with those from the southern basin at the same depths, while the concentrations of ${ }^{3} \mathrm{H}$ and ${ }^{3} \mathrm{He}$ are significantly different between basins. The long-term mean rate of deep-water renewal is approximately the same in the central and southern basin. In both basins the deep water below $200 \mathrm{~m}$ is exchanged by water from the seasonal mixed layer within $15 \mathrm{yr} \pm 7 \%$, which corresponds to a volume flux of $770 \mathrm{~km}^{3} \mathrm{yr}^{-1}$ in the central basin and of $2220 \mathrm{~km}^{3} \mathrm{yr}^{-1}$ in the southern basin.

The low temperatures in the deep water of the Caspian Sea suggest that convection contributes to deep-water renewal. However, seasonal cooling apparently does not produce sufficient buoyancy to generate deep-water convection within the basins. Large scale mixing can occur only if surface water is exceptionally cold, has an increased salinity, or is loaded by suspended particles.

Because central-basin water has a larger density than southern basin water transport of water from the central basin across the sill towards the south leads to convection down to $400 \mathrm{~m}$ depth in the southern basin in September. Between late fall and spring this process might result in transport of water down to maximum depth in the southern basin. Within the central basin deep water convection might be generated when salinity of the surface water increases during ice formation in early winter. To obtain experimental evidence of the relevance of these processes for the overall vertical exchange, cruises to the Caspian Sea should be carried out between late fall and spring providing detailed CTD measurements from near the ice boundary and across the sill between central and southern basin. 


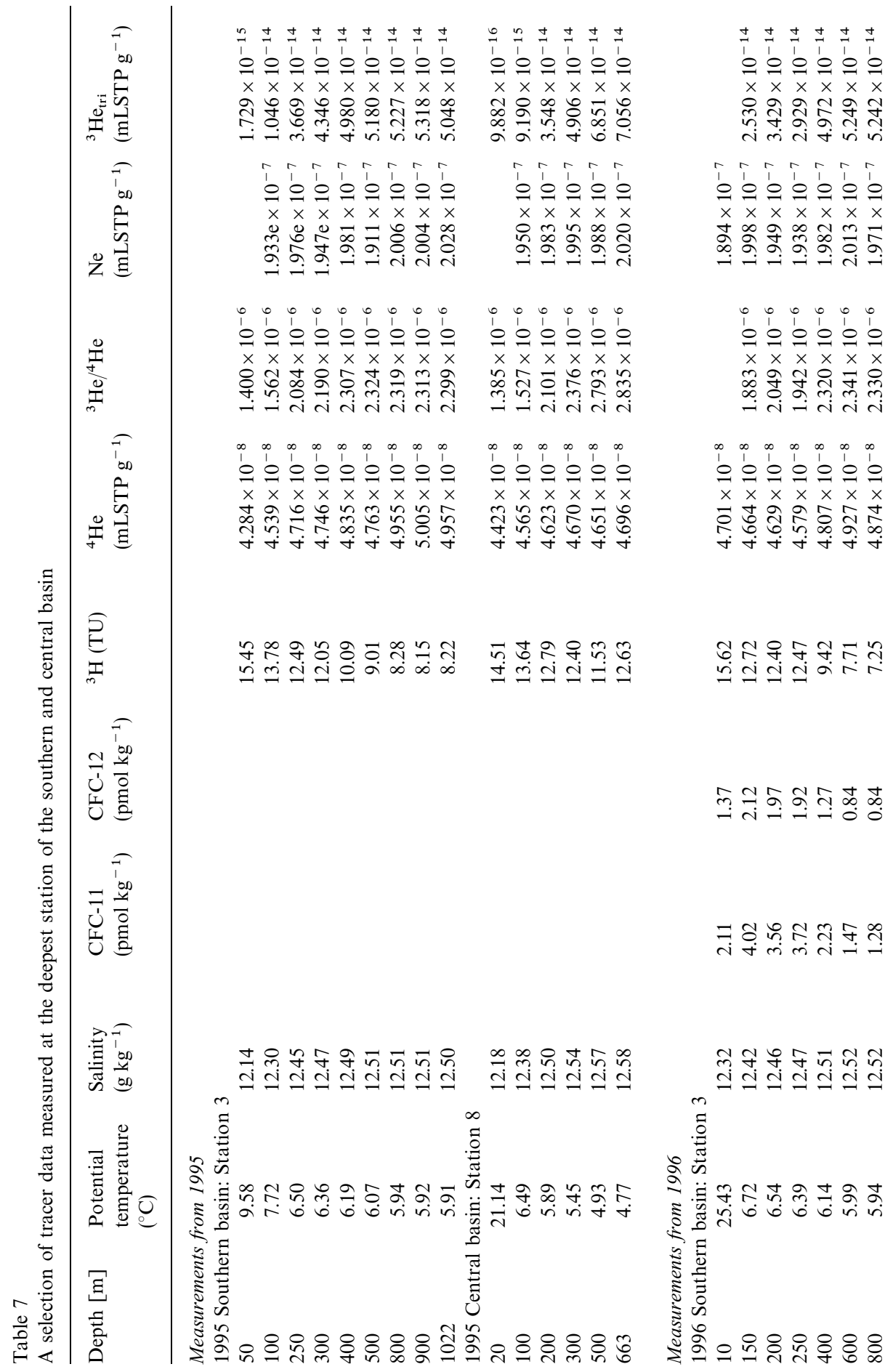




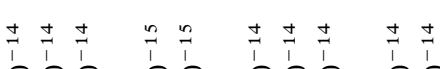

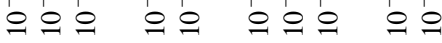
$\times \times \times \times \times \times \times \times \times$

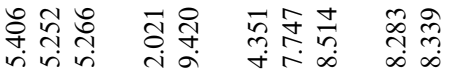
으응으응ㅇㅇ의으 $\times \times \times \times \times \times \times \times \times \times$

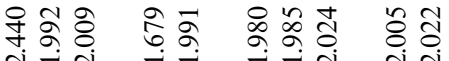

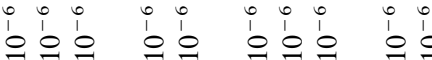
$\times \times \times \times \times \quad \times \times \times \times \times$ సैच

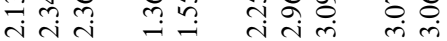

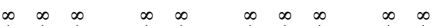

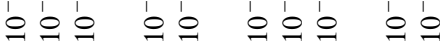
$\times \times \times \times \times \quad \times \times \times \times \times$

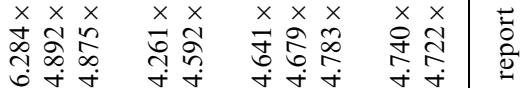

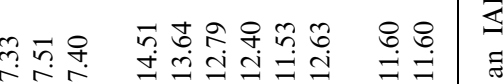

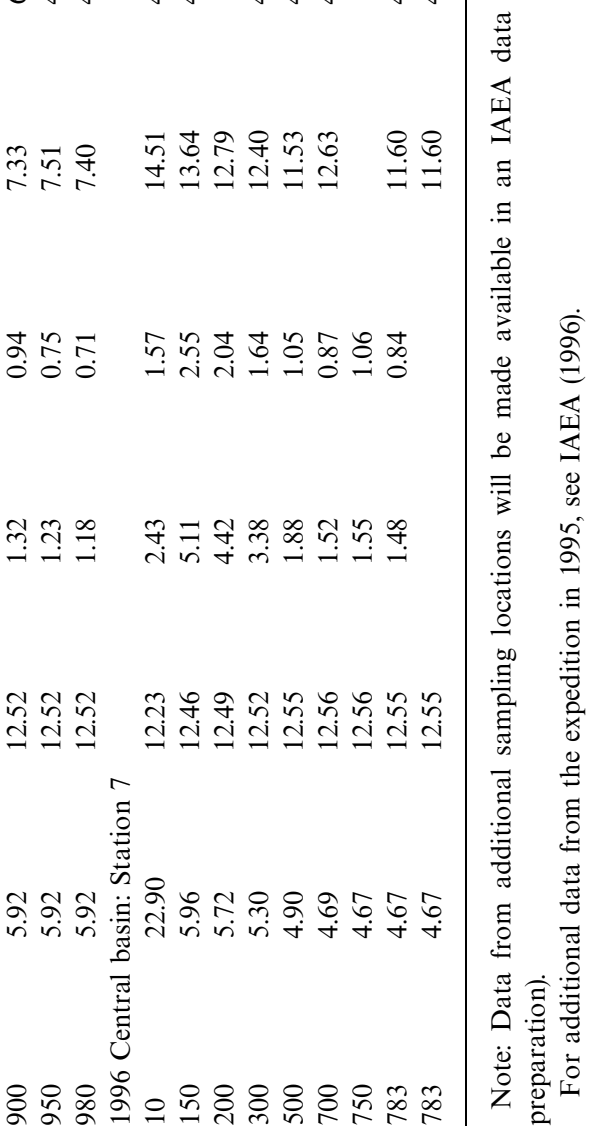


Deep-water renewal in the Caspian Sea might be an intermittent process with rare large scale convective mixing events. The residence time of water below $500 \mathrm{~m}$ depth is in good agreement with a major mixing event in 1976 observed by Kosarev and Yablonskaya (1994). It is reasonable to assume that no major mixing has occurred since then, because already in 1978 the level of the Caspian Sea began to rise. The sea level rise leads to a decrease in surface-water salinity and thus reduces the probability of large-scale convective mixing. Water ages in the deep water below $500 \mathrm{~m}$ depth increased by about 1 yr from September 1995 until September 1996 suggesting that only very little renewal occurred during this time period. In order to find out whether the water below $500 \mathrm{~m}$ depth has been mixed since 1996 new water samples should be collected and analysed for $\mathrm{CFC}-12$ or ${ }^{3} \mathrm{H}$ and ${ }^{3} \mathrm{He}$.

Based on apparent water ages oxygen depletion in the deep-water region below $200 \mathrm{~m}$ was estimated to be on the order $0.35 \mathrm{mg}^{-1} \mathrm{yr}^{-1}$. Because variations in sea level probably influence the rate of deep-water renewal, levels of dissolved oxygen in the deep water most likely are affected by sea-level fluctuations.

\section{Acknowledgements}

The authors express their thanks to N. Clauer and collegues of the Centre of Geochimie de la Surface, CNRS, France, who kindly allowed us to use their data on chemistry. This project was supported by the International Atomic Energy Agency (IAEA), the Swiss Federal Institute for Environmental Science and Technology (EAWAG), the Swiss Federal Institute of Technology (ETH), and a personal research grant to F. Peeters from the Deutsche Forschungsgemeinschaft (DFG).

\section{Appendix A}

Table 7 gives the tracer data.

\section{References}

Aeschbach-Hertig, W., 1994. Helium und Tritium als Tracer für physikalische Prozesse in Seen. Ph.D. Thesis 10714, Swiss Fed. Inst. of Technol. (ETH), Zürich, 272 pp.

Aeschbach-Hertig, W., Kipfer, R., Hofer, M., Imboden, D.M., Baur, H., 1996. Density-driven exchange between the basins of Lake Lucerne (Switzerland) traced with the ${ }^{3} \mathrm{H}-{ }^{3} \mathrm{He}$ method. Limnology and Oceanography 41, 707-721.

Aeschbach-Hertig, W., Peeters, F., Beyerle, U., Kipfer, R., 1999. Interpretation of dissolved atmospheric noble gases in natural waters. Water Resources Research, in press.

Benson, B.B., Krause, D., 1980. Isotopic fractionation of helium during solution: A probe for the liquid state. Journal of Solution Chemistry 9, 895-909.

Bieri, R.H., 1971. Dissolved noble gases in marine waters. Earth and Planetary Science Letters 10, 329-333.

Blinov, L.K., 1962. The physico-chemical properties of Caspian waters and their comparable characteristics. Trudi Gos. Okeanograf. Inst. (GOIN) 68, 7-28. 
Busenberg, E., Plummer, L.N., 1992. Use of chlorofluorocarbons $\left(\mathrm{CCl}_{3} \mathrm{~F}\right.$ and $\left.\mathrm{CCl}_{2} \mathrm{~F}_{2}\right)$ as hydrologic tracers and age-dating tools: the alluvium and terrace system of central Oklahoma. Water Resources Research 28, 2257-2284.

Clever, H.L. (Ed.), 1979. Krypton, Xenon and Radon - Gas Solubilities. Solubility Data Series., Vol. 2. International Union of Pure and Applied Chemistry, Pergamon Press, Oxford.

Culkin, F., Smith, N.D., 1980. Determination of the concentration of potassium chloride solution having the same electrical conductivity, at $15^{\circ} \mathrm{C}$ and infinite frequency, as standard sea water of salinity 35.0000 (Chlorinity 19.37394). IEEE Journal of Oceanic Engineering OE-5 (1), 2.

Dumont, H., 1995. Ecocide in the Caspian Sea. Nature 377, 673-674.

Elkins, J.W., Thompson, T.M., Swanson, T.H., Butler, J.H., Hall, B.D., Cummings, S.O., Fischer, D.A., Raffo, A.G., 1993. Decrease in the growth rates of atmospheric chlorofluorocarbons 11 and 12. Nature 364, 780-783.

Gill, A.E., 1982. Atmosphere-Ocean Dynamics. Academic Press, San Diego, 662 pp.

Hofer, M., Imboden, D.M., 1998. Simultaneous determination of CFC-11, CFC-12, $\mathrm{N}_{2}$, and Ar in water. Analytical Chemistry 70, 724-729.

Hohmann, R., Hofer, M., Kipfer, R., Peeters, F., Imboden, D.M., 1998. Distribution of helium and tritium in Lake Baikal. Journal of Geophysical Research 103 (C6), 12823-12838.

IAEA, 1996. Research/Training on the Caspian Sea. Data Report 1995. International Atomic Energy Agency, Wien, 95 pp.

Katz, B.G., Lee, T.M., Plummer, L.N., Busenberg, E., 1995. Chemical evolution of groundwater near a sinkhole lake, northern Florida. 1. Flow patterns, age of groundwater, and influence of lake water leakage. Water Resources Research 31, 1549-1564.

Kipfer, R., Aeschbach-Hertig, W., Baur, H., Hofer, M., Imboden, D.M., Signer, P., 1994. Injection of mantle type helium into Lake Van (Turkey): The clue for quantifying deep water renewal. Earth and Planetary Science Letters 125, 357-370.

Klinge, R.K., Myagkov, M.S., 1992. Changes in the water regime of the Caspian Sea. Geojournal 23, 299-307.

Kosarev, A.N., Tuhylkin, V.C., 1995. Climatic Thermohaline Fields of the Caspian Sea. Hydrometeorological Service of Russia, Moscow, $122 \mathrm{pp}$.

Kosarev, A.N., Yablonskaya, E.A., 1994. The Caspian Sea. The Hague, SPB Academic Publishing, 274 pp.

Millero, F.J., Chetirkin, P.V., 1980. The density of Caspian Sea waters. Deep-Sea Research 27A, 265-271.

Montzka, S.A., Butler, J.H., Myers, R.C., Thompson, T.M., Swanson, T.H., Clarke, A.D., Lock, L.T., Elkins, J.W., 1996. Decline in the tropospheric abundance of halogen from halocarbons: implications for stratospheric ozone depletion. Science 272, 1318-1322.

Oliver, B.M., Bretscher, M.M., Farrar, H., 1989. Mass spectrometric determination of the absolute tritium activities of NBS tritiated water standards. Applied Radiational Isotopes 40 (3), 199-208.

O'Nions, R.K., Oxburgh, E.R., 1983. Heat and helium in the earth. Nature 306, 429-431.

Peeters, F., Kipfer, R., Hohmann, R., Hofer, M., Imboden, D.M., Kodenev, Khozder, T., 1997. Modelling transport rates in Lake Baikal: gas exchange and deep water renewal. Environmental Science Technology 31, 2973-2982.

Rodionov, S.N., 1994. Global and Regional Climate Interaction: the Caspian Sea Experience. Water Science and Technology Library, Kluwer Academic Publisher, Dordrecht, 241 pp.

Smith, S.P., Kennedy, B.M., 1983. Solubility of noble gases in water and in $\mathrm{NaCl}$ brine. Geochemica Cosmochimica Acta 47, 503-515.

Torgersen, T., Top, Z., Clarke, W.B., Jenkins, W.J., Broecker, W.S., 1977. A new method for physical limnology - tritium-helium-3 ages - results for Lakes Erie, Huron and Ontario. Limnology and Oceanography 22, 181-193.

UNESCO, ICES, SCOR, IAPSO, 1981a. Background papers and supporting data on the international equation of state of seawater 1980. Unesco technical papers in marine science, Nr. 38, UNESCO.

UNESCO, ICES, SCOR, IAPSO, 1981b. Background papers and supporting data on the practical salinity scale 1978. Unesco technical papers in marine science, Nr. 37, UNESCO.

Warner, M.J., Weiss, R.F., 1985. Solubilities of chlorofluorocarbons 11 and 12 in water and seawater. Deep-Sea Research 32, 1485-1497. 
Weiss, R.F., 1970. The solubility of nitrogen, oxygen and argon in water and seawater. Deep-Sea Research 17, 721-735.

Weiss, R.F., 1971. Solubility of helium and neon in water and seawater. Journal of Chemical Engineering Data 16, 235-241.

Weiss, R.F., Carmack, E.C., Koropalov, V.M., 1991. Deep-water renewal and biological production in Lake Baikal. Nature 349, 665-669.

Wüest, A., Piepke, G., Halfman, J.D., 1996. Combined effects of dissolved solids and temperature on the density stratification of Lake Malawi. In: Johnson, T.C., Odada, E.O. (Eds.), The Limnology, Climatology and Paleoclimatology of the East African Lakes. Gordon and Breach, Toronto, pp. 183-202. 